\title{
p63 Isoforms Regulate Metabolism of Cancer Stem Cells
}

Simona D’Aguanno, ${ }^{\dagger, \ddagger}$ Daniela Barcaroli, ${ }^{\dagger, \S}$ Claudia Rossi, ${ }^{\dagger, \S}$ Mirco Zucchelli, ${ }^{\dagger, \S}$ Domenico Ciavardelli,, , \# Claudio Cortese, ${ }^{\ddagger, \|}$ Antonella De Cola, ${ }^{\dagger, \S}$ Silvia Volpe, ${ }^{\perp}$ Daniela D’Agostino, ${ }^{\dagger, \S}$ Matilde Todaro, ${ }^{\perp}$ Giorgio Stassi, ${ }^{\perp}$ Carmine Di Ilio, ${ }^{\dagger, \S}$ Andrea Urbani, $*,+, \|, \nabla$ and Vincenzo De Laurenzi ${ }^{*}, \dagger, \S, \nabla$

${ }^{\dagger}$ Department of Experimental and Clinical Sciences, “G. d’Annunzio University”, Via dei Vestini 31, Chieti-Pescara 66100, Italy

${ }^{\ddagger}$ Fondazione Santa Lucia-IRCSS, Via Ardeatina 306, Rome 00142, Italy

${ }^{\S}$ Centre of Study on Aging (Ce.S.I.), “G. d’Annunzio” University Foundation,Via dei Vestini 31, Chieti 66100, Italy

"Department of Experimental Medicine, University of Rome “Tor Vergata”, Via Montpellier 1, Rome 00133, Italy

${ }^{\perp}$ Department of Surgical and Oncological Sciences, University of Palermo, Via del Vespro 129, Palermo 90100, Italy

"University of Enna “Kore”, Via delle Olimpiadi, Enna 94100, Italy

\section{Supporting Information}

ABSTRACT: p63 is an important regulator of epithelial development expressed in different variants containing (TA) or lacking $(\Delta \mathrm{N})$ the $\mathrm{N}$-terminal transactivation domain. The different isoforms regulate stem-cell renewal and differentiation as well as cell senescence. Several studies indicate that p63 isoforms also play a role in cancer development; however, very little is known about the role played by p63 in regulating the cancer stem phenotype. Here we investigate the cellular signals regulated by TAp63 and $\Delta$ Np63 in a model of epithelial cancer stem cells. To this end, we used colon cancer stem cells, overexpressing either TAp63 or $\Delta \mathrm{Np} 63$ isoforms, to carry out a proteomic study by chemical-labeling approach coupled to network analysis. Our results indicate that p63 is implicated in a wide range of biological processes, including metabolism. This was further investigated by a targeted strategy at both protein and metabolite levels. The overall data show that TAp63 overexpressing cells are more glycolytic-active than $\Delta$ Np63 cells, indicating that the two isoforms may regulate the key steps of glycolysis in an opposite manner. The mass-spectrometry proteomics data of the study have been deposited to the ProteomeXchange Consortium (http://proteomecentral. proteomexchange.org) via the PRIDE partner repository with data set identifiers PXD000769 and PXD000768.

KEYWORDS: p63, colon cancer stem cells, proteomics, stable isotope dimethyl labeling, glucose metabolism

\section{INTRODUCTION}

The $\mathrm{p} 53 / \mathrm{p} 63 / \mathrm{p} 73$ family is composed of strictly related transcription factors sharing highly homologous sequences. Thus it was supposed for a long time that these proteins could also share functional roles. ${ }^{1,2}$ In recent years, distinct roles for each member have emerged on the basis of new experimental evidence. A huge number of studies demonstrated that p53 is a master tumor suppressor gene, whose mutation is frequently associated with cancer, ${ }^{3}$ while the role of p63 in tumor suppression still needs more clarification. The study of the role played by $\mathrm{p} 63$ is sometimes rendered more problematic by the structural variability of protein products originating from $\mathrm{p} 63$ gene. Similarly to p73, p63 gene is transcribed in multiple isoforms. The amino-terminal region of p63 may include an acidic transactivation domain (TA isoforms) or lack this domain $\left(\Delta \mathrm{N}\right.$ isoforms). ${ }^{4}$ Moreover alternative splicing may originate different transcripts responsible for variability at protein carboxy-terminals, thus bringing about $\alpha, \beta, \gamma, \delta$, and $\varepsilon$ variants. From a structural point of view, p63 $\alpha$ is closer to p73 $\alpha$, sharing a common sterile alpha motive (SAM) domain, absent in p53. TAp63 and $\Delta \mathrm{Np} 63$ regulate to different extent the expression of their targets, which are involved in several cellular functions such as apoptosis, cell cycle arrest, and senescence. ${ }^{4,5}$

Altered levels of p63 were demonstrated in different epithelial tumors, such as in breast, head and neck, and lung, by the use of targeted detection techniques, such as PCR, or by using antibodies, which could not discriminate among TAp63 and $\Delta \mathrm{Np} 63$, thus sometimes giving controversial results. ${ }^{6}$ In particular, these studies showed that the TA isoforms are not expressed or weakly expressed, whereas the $\Delta \mathrm{N}$ isoforms are expressed at higher levels. ${ }^{6,7}$ Conversely to p53, mutations of p63 are extremely rare in tumors. ${ }^{7}$ The expression pattern showed by the different isoforms observed in cancer is consistent with the concept that TAp63 $\alpha$ may function as

Received: December 18, 2013

Published: March 5, 2014 


\section{Scheme 1. Workflow Diagram Showing the Experimental Design}

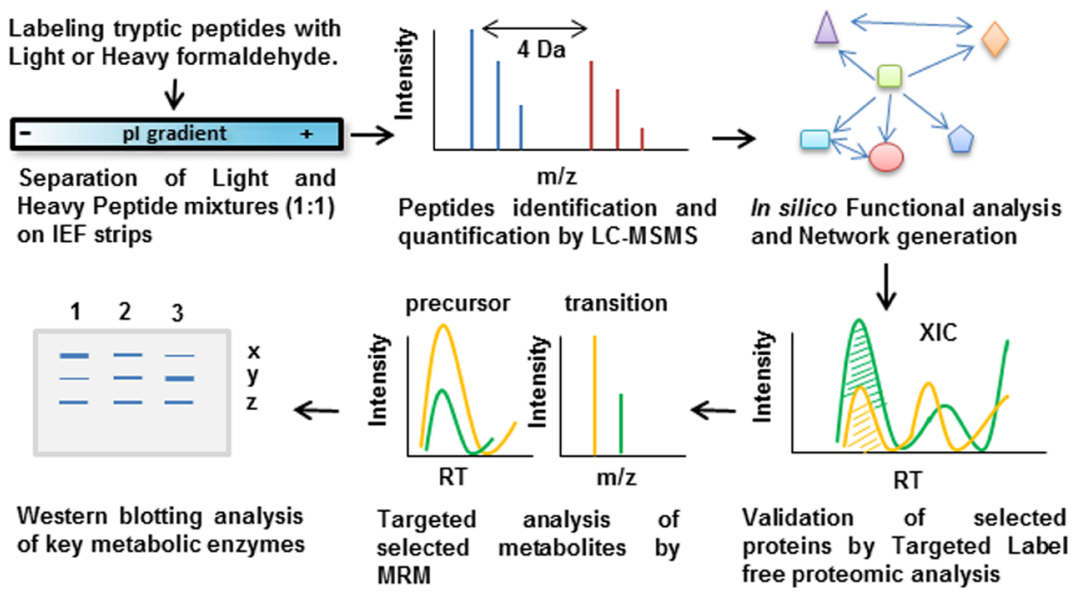

tumor suppressor, while $\Delta \mathrm{Np} 63 \alpha$ may act as an oncogene, antagonizing p53, TAp63, and TAp73, by affecting the expression of those target genes, which are generally under their control; ${ }^{8}$ this, however, is probably an oversimplified vision of how these transcription factors work, and indeed $\Delta \mathrm{Np} 63$ contains an additional transactivation domain and has been shown to up-regulate expression of a specific set of genes. ${ }^{8}$ Evaluation of p63 expression profile also revealed in a few cases the lack of the $\Delta \mathrm{Np} 63$ protein in human tumors such as diffuse large B-cell lymphoma (DLBCL), suggesting that this isoform may also acts as a tumor suppressor. ${ }^{9}$ The epithelial mesenchymal transition (EMT), a relevant process involved in cancer cell metastasis as well as in embryogenesis, is also known to be modulated by $\Delta \mathrm{Np} 63$. As an example, it was reported in a model of squamous cell carcinoma (SCC) that during EMT, SNAIL, a regulator of cellular invasiveness, downregulates $\Delta \mathrm{Np} 63$ expression and in parallel also down-regulates E-cadherin. ${ }^{10}$ Recently, experiments conducted in prostate cancer cells showed that both TAp63 and $\Delta$ Np63 isoforms regulate expression of miR-205, which is essential for p63 to explain its inhibitory effect on EMT. ${ }^{11}$ In vitro and in vivo experiments revealed that TAp63 is a suppressor of tumorigenesis and metastasis. ${ }^{12}$ According to the proposed model, TAp63 transcriptionally activates metastasis suppressor genes or microRNAs, such as DICER1, mir-130b, and BHLHE41, also known as SHARP1, and genes involved in integrin recycling. The suppression of the metastasis mediated by TAp63 is inhibited by aggregation with mutant p53 and by transforming growth factor- $\beta$ (TGF $\beta){ }^{8,12}$ p63 was also reported to be involved in cancer chemosensitivity. ${ }^{5}$ Endogenous TAp63 expression was increased after drug treatment in hepatoma cells, and the abrogation of TAp63 function caused enhanced chemoresistance. These observations were in accordance with the pro-apoptotic activity of TAp63, carried out through death receptor- and mitochondrial-mediate apoptosis pathway. ${ }^{13}$ On the contrary, $\Delta \mathrm{Np} 63$ does not show pro-apoptotic activity but can compete with TAp63 for the same responsive element, thus inhibiting the TAp63-mediated apoptotic program. ${ }^{14}$

A large plethora of experimental research regarding p63 function focused not only on its involvement in cancer but also on characterizing its pivotal role in epithelial development. ${ }^{5}$ Mutant mice that do not express p63 are born lacking limbs as well as skin and its appendages ${ }^{15,16}$ and have markedly abnormal prostate and bladder epithelia. ${ }^{17}$ More deepen understanding about the distinct functions of the two isoforms, achieved by the characterization of knockout mice for TA and $\Delta$ Np63 isoforms, revealed that these anomalies result from the lack of $\Delta \mathrm{Np} 63 .^{18} \Delta \mathrm{Np} 63$ is expressed in basal epithelial cells and is required for normal development of several epithelial tissues, including the bladder, prostate glands and colorectal epithelia. ${ }^{19}$ This isoform is necessary for stem-cell renewal ${ }^{15,20}$ as well as for terminal differentiation, ${ }^{18,21}$ whereas TAp63 is implicated in maintaining stem cells in quiescence and preventing premature aging ${ }^{22}$ and senescence. ${ }^{1222}$ Because of its implication in both cancer and stemness, p63 may also play a relevant role in maintaining the cancer stem-cell phenotypes, particularly in tumors of epithelial origin. ${ }^{6,14,23}$ Colorectal tumors are hierarchically organized with a minor cancer stem cells (CSCs) niche, showing self-renewal and multilineage differentiation capacity, responsible for the formation of more differentiated less malignant cells, making up the bulk of the tumor. $^{24,25}$ CSCs have also been implicated in drug resistance and tumor recurrence, although the nature of this relationship is only beginning to be clarified. ${ }^{26}$ Onco-proteomics may significantly contribute to explore this field, employing sensitive methodological approaches and accurate procedures to characterize proteins involved in the cellular processes responsible for maintaining the CSC pool. ${ }^{27}$

In this work, we investigated the effects of TAp63 $\alpha$ and $\Delta \mathrm{Np} 63 \alpha$ overexpression in colon CSCs, which express a low level of the endogenous isoforms by complementary proteomics approaches (Scheme 1). In the discovery phase, we carried out a quantitative proteome analysis by stable isotope dimethyl labeling to define the expression profiles of the infected cells, generating raw data for unsupervised datamining of functional biological processes. Then, in a subsequent validating phase, we employed a targeted analysis, at both protein and metabolite levels, focusing, in particular, on metabolic processes. This experimental design allowed us to obtain an overview on cellular pathways modulated by p63, thereby offering the opportunity to better understand its implication in maintaining the CSCs phenotype.

\section{EXPERIMENTAL PROCEDURES}

\section{Purification and Culture of CSCs}

Human colon tissue fragments were obtained in accordance with the ethical standards of the institutional committee on human experimentation from a patient undergoing a colon 
resection for colon adenocarcinoma. Histological diagnosis was based on microscopic features of carcinoma cells determining the histological type and grade. Cancer tissues were extensively washed in saline buffer containing antibiotics and incubated overnight in DMEM/F12 (1:1) containing penicillin (500 IU/ $\mathrm{mL})$, streptomycin $(500 \mu \mathrm{g} / \mathrm{mL})$ and amphotericin B $(1.25 \mu \mathrm{g} /$ $\mathrm{mL})$. Enzymatic digestion was performed using collagenase (1.5 $\mathrm{mg} / \mathrm{mL})$ and hyaluronidase $(20 \mu \mathrm{g} / \mathrm{mL})$ in DMEM containing antibiotics/antimycotics for $1 \mathrm{~h}$. Recovered cells were then cultured in serum-free medium DMEM/F12 (1:1) supplemented with $6 \mathrm{mg} / \mathrm{mL}$ glucose, $1 \mathrm{mg} / \mathrm{mL} \mathrm{NaHCO}_{3}, 5 \mathrm{mM}$ HEPES, $2 \mathrm{mM}$ L-glutamine, $4 \mu \mathrm{g} / \mathrm{mL}$ heparin, $4 \mathrm{mg} / \mathrm{mL}$ BSA, $10 \mathrm{ng} / \mathrm{mL} \quad \beta$ FGF, $20 \mathrm{ng} / \mathrm{mL}$ EGF, $100 \mu \mathrm{g} / \mathrm{mL}$ transferrin sodium salt, $25 \mu \mathrm{g} / \mathrm{mL}$ insulin, $9.6 \mu \mathrm{g} / \mathrm{mL}$ putrescine, $30 \mathrm{nM}$ sodium selenite, and $20 \mathrm{nM}$ progesterone to a final concentration of $3 \times 10^{5}$ cells $/ \mathrm{mL}$ at $37{ }^{\circ} \mathrm{C}$ in a humidified atmosphere of $5 \%(\mathrm{v} / \mathrm{v}) \mathrm{CO}_{2}$ in air. These culture conditions select for immature tumor cells that slowly proliferate, giving rise, within 2 to 3 months, to tumor cell aggregates, called "spheres". 28

\section{Plasmids}

TAp63 $\alpha$-Tween and $\Delta$ Np63 $\alpha$-Tween expression vectors were generated from TAp $63 \alpha-\mathrm{pcDNA}$ and $\Delta \mathrm{Np} 63 \alpha-\mathrm{pcDNA}$ constructs, kindly provided by Prof. G. Melino, University of Rome "Tor Vergata", Roma, Italy. ${ }^{29}$ Inserts were subcloned into XbaI-Xhol unique sites of Tween lentiviral vector ${ }^{30}$ under the control of hCMV promoter. This vector constitutively expresses GFP under the control of hPGK promoter.

\section{Lentiviral Trasduction and Flow Cytometry}

Lentiviral supernatants were produced by transient cotransfection of a three-plasmid expression system in the packaging 293T cell line, using the calcium phosphate transfection kit (K2780-01, Invitrogen). The calcium phosphate-DNA precipitate was removed after $9 \mathrm{~h}$ by washing once in PBS and replacing the medium. Viral supernatant was collected $48 \mathrm{~h}$ after transfection, filtered through $0.45 \mu \mathrm{m}$ pore nitrocellulose filter. CSCs were plated in a six-well plate in the presence of viral supernatant and $4 \mu \mathrm{g} / \mathrm{mL}$ of polybrene. Plates were centrifuged for $45^{\prime}$ at 1800 revolutions/min and incubated at $37^{\circ} \mathrm{C}$ for $75^{\prime}$ in a $5 \% \mathrm{CO} 2$ incubator. Cells were then washed twice and replated in fresh medium. ${ }^{31}$ Transduction efficiency was assessed as the percentage of GFP-positive cells measured by flow cytometry (FACSCanto II Instrument, BD Biosciences) $48 \mathrm{~h}$ postinfection. Data were analyzed with CELLQuest software (BD Biosciences).

\section{Peptides Labeling}

Cells of three independent infection experiments for each condition were lysed by sonication, and total proteins were extracted in $6 \mathrm{M}$ urea, $100 \mathrm{mM}$ Tris $/ \mathrm{HCl} \mathrm{pH} 7.5$ buffer. Protein concentration was determined by the Bio-Rad Protein Assay (Bio-Rad Laboratories, Hercules, CA). $50 \mu \mathrm{g}$ for each of the three protein extractions was pooled for condition, precipitated by the addition of a mix of ethanol, methanol, and acetone (ratio 2:1:1, v/v/v) and solubilized in $6 \mathrm{M}$ urea, $100 \mathrm{mM}$ TEAB pH 8.5, a buffer compatible with subsequent dimethylation. ${ }^{32} 25 \mu \mathrm{L}$ of $6 \mathrm{M}$ urea, $100 \mathrm{mM}$ TEAB $\mathrm{pH} 8.5$, containing $100 \mu \mathrm{g}$ of pooled protein extract was reduced and alkylated by adding DTT $(10 \mathrm{mM})\left(1 \mathrm{~h}\right.$ at $\left.36{ }^{\circ} \mathrm{C}\right)$ and iodoacetamide $(50 \mathrm{mM})(1 \mathrm{~h}$ at $\mathrm{RT})$. Protein samples were digested with 1:20 (w/w) sequence grade trypsin (Promega, Madison, WI) at $36{ }^{\circ} \mathrm{C}$ overnight. Tryptic peptides were subjected to chemical labeling by modifying the already published protocol. ${ }^{32,33}$ Stable isotope dimethyl labeling was achieved by the reaction of peptide primary amines (the $\mathrm{N}$ terminus and the side chain of lysine residues) with formaldehyde to generate a Schiff base, rapidly reduced by adding cyanoborohydride to the tryptic digestion. Light labeled peptides were obtained by using formaldehyde- $D_{0}$ and cyanoborohydride, which produced a mass increase of $28 \mathrm{Da}$, while the use of deuterated formaldehyde (formaldehyde- $D_{2}$ ) generated a mass increase of $32 \mathrm{Da}$, achieving the heavy labeled samples. The labeled samples can then be mixed because the different isotopes do not affect the behavior of the labeled peptides in LC-MS/MS. An insignificant isotopic effect in chromatography runs has been verified by $\mathrm{Hsu}$ at colleagues ${ }^{33}$ and by other subsequent dedicated studies, ${ }^{34}$ so that the coelution of paired labeled peptides (the pair of heavy and light peptide) is expected to occur.

In MS, the different stable isotopically labeled peptides can be recognized by the known mass difference between them. Finally, quantification can be performed by comparing the signal intensity of the differentially labeled peptides. In detail: $1.5 \mu \mathrm{L}$ of formaldehyde- $D_{0}$ (20\% in water) was mixed in the peptides mixture, vortexed, and incubated for $5 \mathrm{~min}$ at RT. Then, $2.5 \mu \mathrm{L}$ of freshly prepared sodium cyanoborohydride (1 $\mathrm{M})$ was added and allowed to react for $1 \mathrm{~h}$ at RT. Deuterium labeling was performed by similar procedure but by using formaldehyde- $D_{2}$ (20\% in water). An extensive characterization of dimethylation in quantitative analysis has been recently performed by our group, ${ }^{35}$ demonstrating, in accordance with other published works, ${ }^{32,33}$ that this approach is cheap, quick, and applicable to any sample, including complex samples. The completion of the reaction was evaluated by running singularly the $D_{0^{-}}$and $D_{2}$-labeled samples in $\mathrm{nL}-\mathrm{MS} / \mathrm{MS}$ by using a $\mathrm{Q}^{-}$ Tof Premier mass spectrometer (Waters, Manchester, U.K.) operating in DDA mode. ${ }^{36}$ In the case of complete $D_{0}$ or $D_{2}$ reaction, it is expected that all peptides will be dimethylated (at $\mathrm{N}$-terminus) or tetramethylated (both at $\mathrm{N}$-terminus and at the side chain of lysine residue). By including dimethylation at the $\mathrm{N}$-terminus and side chain of lysine residue as a variable modification in the database search, all peptides of $D_{0^{-}}$and $D_{2}$ labeled samples were found to be modified (representative database search results were reported in Supplementary Table $1 S$ in the Supporting Information). On the contrary, when these modifications were not applied, we did not obtain peptide identification.

Light and heavy labeled samples were mixed 1:1 prior to peptide separation by isoelectric focusing. We analyzed TAp63$D_{0}$ with CTRL- $D_{2}(1: 1)$ and $\Delta$ Np63- $D_{0}$ with CTRL- $D_{2}(1: 1)$. The inverted labeled samples were also mixed: TAp63- $D_{2}$ with CTRL- $D_{0}(1: 1)$ and $\Delta$ Np63- $D_{2}$ with CTRL- $D_{0}(1: 1)$.

Immobilized pH Gradient Isoelectric Focusing (IPG-IEF) Separation of Labeled Peptides

Mixed samples of light and heavy labeled peptides were separated by IPG-IEF prior to mass spectrometry analysis. ${ }^{37-39}$ A solution of $8 \mathrm{M}$ urea, $0.5 \%$ (v/v) IPG-buffer ( $\mathrm{pH} 3-10 \mathrm{NL}$, Amersham Biosciences, Buckinghamshire, U.K.), and bromophenol blue in traces was added to the mixture of labeled peptides until a final volume of $350 \mu \mathrm{L}$. Isoelectric focusing was performed in an IPGphor system (Amersham Biosciences) using Immobiline Dry strips $18 \mathrm{~cm}, \mathrm{pH}$ interval 3-10 nonlinear at $20{ }^{\circ} \mathrm{C}$. After $8 \mathrm{~h}$ of passive and $8 \mathrm{~h}$ of active rehydration at 30 $\mathrm{V}$, peptides were focused ramping to $300 \mathrm{~V}$ over $2 \mathrm{~h}$, holding at 
$300 \mathrm{~V}$ for $1 \mathrm{~h}$, ramping to $3500 \mathrm{~V}$ over $3 \mathrm{~h}$, holding at $3500 \mathrm{~V}$ for $3 \mathrm{~h}$, successively ramping to $8000 \mathrm{~V}$ over $3 \mathrm{~h}$ and plateau at $8000 \mathrm{~V}$ until $50000 \mathrm{~V} / \mathrm{h}$.

\section{nLC-MS/MS Analysis}

Focused strips were cut into $15-17$ pieces, and peptides were extracted twice with a solution of $0.1 \%$ formic acid (FA) and $50 \%$ acetonitrile (1:1) and then with $100 \%$ acetonitrile, collecting supernatants into autosampler vials. The extracted mixtures were dried by Speed-Vac and dissolved in $20 \mu \mathrm{L}$ of $0.1 \%$ FA. Five microliters of each sample was separated by a Proxeon Easy-nLC II (Thermo Scientific, Waltham, MA) chromatographic system equipped with an EASY-Column C18, $5 \mu \mathrm{m}, 100 \mu \mathrm{m} \times 20 \mathrm{~mm}$ precolumn (Thermo Scientific) and using an Acclaim PepMap100 C18, $5 \mu \mathrm{m}, 75 \mu \mathrm{m} \times 25 \mathrm{~mm}$ (Dionex, Thermo Scientific) nanoscale LC column. Mobile phase A was water with $0.1 \% \mathrm{FA}$, and mobile phase B was $0.1 \%$ FA in acetonitrile. Peptides were separated with a reverse-phase gradient of 5-35\% mobile phase B over $57 \mathrm{~min}$ at a flow rate of $300 \mathrm{~nL} / \mathrm{min}$ and a rinse with $100 \%$ mobile phase $\mathrm{B}$ for $10 \mathrm{~min}$. The chromatographic system was coupled online to a MicrOTOF Q-II mass spectrometer (Bruker-Daltonics, Bremen, Germany) equipped with an ESI nanosprayer ion source. During acquisition, source settings were: end plate offset: -500 $\mathrm{V}$; capillary $=4500 \mathrm{~V}$; nebulizer $=0.4$ bar; dry gas $=4 \mathrm{~L} / \mathrm{min}$; dry temperature $=160{ }^{\circ} \mathrm{C}$.

Spectra acquisition in the mass range $400-1400 \mathrm{~m} / \mathrm{z}$ was performed by using an Auto (MS/MS) mode method optimized for quantitative proteomics (Bruker-Daltonics, Bremen, Germany), setting MS spectra rate to $1.0 \mathrm{~Hz}$ and the number of precursor ions to 5, using active exclusion after two spectra, using Argon in collision gas cell, and selecting the SILE option. By this option, it is possible to define the delta mass introduced by the labeling approach. A delta mass of $4 \mathrm{Da}$ indicates the N-terminal dimethylation, while a delta mass of 8 $\mathrm{Da}$ indicates the dimethylation of both $\mathrm{N}$-terminal and lysine residue of the peptide sequence, and thus in the SILE option we specified delta mass $=4.0251$; maximum number of labels $=$ 2 ; and charge range $=1-3$.

\section{Peptide Identification and Quantification}

Spectra were processed by using Mascot Distiller v2.4.3.3 using the default processing methods optimized for Q-TOF instrument. Peptide identification was achieved by the in-house version of Mascot algorithm (version 2.4), interrogating SwissProt database (released version 2013_02) restricted to Homo sapiens taxonomy (20 248 sequences). Search parameters were: carbamidomethylation of cysteines as fixed modification, oxidation of methionines as variable modification, dimethylation as quantitation method, one missing cleavage allowed on tryptic peptides, $20 \mathrm{ppm}$ for peptide tolerance, $0.1 \mathrm{Da}$ for fragment tolerance, $p$ value $<0.05$ for peptide significant value of identification, and decoy option active. Proteins identified with one unique peptide were manually validated. After protein identification, only peptides matching the following criteria were included in the final quantitation analysis: $p$ value $<0.05$ for peptide significant value, bold red, unique sequences, standard error $<0.2$, correlation threshold $>0.9$, and fraction threshold of at least 0.5. Because the fit between the experimental and the calculated peaks is never perfect, Distiller allows us to accept a peptide ratio by applying the threshold of three measures of the quality of the fit: standard error, fraction, and correlation. The standard error is the estimated error for the calculated ratio. The correlation coefficient, which considers the shape of the peak distribution, is the estimation of the good fit between the predicted and observed precursor isotope distributions. Fraction is the fraction of the precursor region accounted for by the expected precursor peaks. The resulting quantified proteins were reported in the quantitation report, where the protein ratio type selected was "median" and the interval of confidence was expressed as geometric standard deviation, SD(geo), which is a factor, not a difference. Finally, only proteins with a ratio $>1.3$ or $<0.7$ and Mascot score above 40 and acceptable $\mathrm{SD}$ (geo) were considered in the further analysis. Proteins were identified with FDR $<1 \%$. The mass spectrometry proteomics data have been deposited to the ProteomeXchange Consortium (http://www. proteomexchange.org) via the PRIDE partner repository ${ }^{40,41}$ with the data set identifier PXD000768 and DOI: 10.6019/ PXD000768 for TAp63 and PXD000769 and DOI: 10.6019/ PXD000769 for $\Delta \mathrm{Np} 63$. These data sets are formally associated with the B/D-HPP initiative on Cancer and Mitochondria.

\section{Bioinformatics Analysis}

Modulated proteins identified by proteomic analysis were further analyzed by the PANTHER Classification System (http://www.pantherdb.org), by The Database for Annotation, Visualization and Integrated Discovery (DAVID) (http:// david.abcc.ncifcrf.gov/), and by Ingenuity Pathway Analysis software v.8.8 (IPA). Using PANTHER resource, it is possible to categorize genes by their molecular functions or biological processes on the basis of published papers and by evolutionary relationships to predict function when experimental evidence is missing. DAVID provides a comprehensive set of functional annotation tools for investigators to understand biological meaning behind a large list of genes/proteins. IPA highlights protein networks or pathways starting from a continuous updated database of known protein-protein interactions based on direct (physical) and indirect (functional) associations. The algorithm gives back a probability score for each possible network. Scores of 10 or higher (negative log of the $p$ value) have a high confidence of not being generated by random chance alone. $^{42-44}$

\section{Targeted Label-Free Quantitative Analysis}

Protein extracts samples were prepared as previously described. Tryptic peptide mixtures of the three different conditions, obtained by in-solution digestion as already described, were separately analyzed by nanoACQUITY UPLC System (Waters, Milford, MA) coupled to a Q-Tof Premier mass spectrometer (Waters, Manchester, U.K.) operating in high-low mode. ${ }^{42-44}$ The triplicate of each condition was run. Prior to loading, a digestion of Enolase (ENO1) from Saccharomyces cerevisiae (Waters) was added to the sample as an internal standard to have a final concentration of $100 \mathrm{fmol} / \mu \mathrm{L}$ on column. A total of $0.6 \mu \mathrm{g}$ of protein digestion was injected onto symmetry $\mathrm{C} 185$ $\mu \mathrm{m}, \quad 180 \mu \mathrm{m} \times 20 \mathrm{~mm}$ as precolumn (Waters) for preconcentration and desalting and separated using a NanoEase BEH C18 $1.7 \mu \mathrm{m}, 75 \mu \mathrm{m} \times 25 \mathrm{~cm}$ nanoscale LC column (Waters) maintained at $35^{\circ} \mathrm{C}$. Mobile phase A was water with $0.1 \%$ formic acid, while mobile phase B was $0.1 \%$ formic acid in acetonitrile. Peptide separation was obtained by a gradient of $3-40 \% \mathrm{~B}$ over $150 \mathrm{~min}$ at flow rate of $250 \mathrm{~nL} / \mathrm{min}$, followed by a gradient of $40-90 \%$ B over $5 \mathrm{~min}$ and a $15 \mathrm{~min}$ rinse with $90 \%$ B. The Q-Tof Premier mass spectrometer was operated in "Expression Mode" switching between low (4 eV) and high $(15-40 \mathrm{eV})$ collision energies with a scan time of $0.8 \mathrm{~s}$ over $50-1990 \mathrm{~m} / \mathrm{z}$ mass range. Continuum LC-MS data were 
processed and searched using ProteinLynx GlobalServer v2.4 (PLGS) (Waters). Protein identifications were obtained with the embedded ion accounting algorithm of the software and by searching a UniProtKB/SwissProt human database. Parameters for the database search were: automatic tolerance for precursor ions, automatic tolerance for product ions, minimum of three fragment ions matched per peptide, minimum of seven fragment ions matched per protein, minimum of two peptides matched per protein, one missed cleavage, carbamidomethylation of cysteine and oxidation of methionine as modifications, and the false positive rate (FPR) of the identification algorithm $<1 \%$.

Acquired raw data were used as input files by Skyline opensource software to perform quantitative analysis. ${ }^{46,47}$ A peptide MS/MS spectral library of samples was created from a csv file generated by PLGS software including peptide and fragment ions information. Duplicate or repeated peptides and peptides without a matching protein in the background proteome, the UniProtKB/Swiss-Prot database restricted to Homo sapiens taxonomy, were automatically removed. Raw data from single sample runs were processed to generate the eXtracted Ion Chromatogram (XIC) of selected peptide masses. Automatic peak assignment and retention times were verified manually. After Savitzky-Golay smoothing, the peaks corresponding to the precursor ion retention times were integrated and the resulting peak areas were normalized to the endogenous actin and then multiplied by a normalization factor of 100 . The normalized peak area was averaged across all acquisitions, and a ratio was generated. $p$ value was calculated by applying Student's $t$-test.

\section{Metabolomics Analysis}

$100 \mu \mathrm{L}$ of a mixture of ethanol/water 80:20 was added to $\sim 5 \times$ $10^{6}$ cell pellets. Pellets were obtained by pooling cells of three independent infection experiments. Cells were sonicated for 20 min; then, samples were centrifuged $\left(25000 \mathrm{~g}, 4{ }^{\circ} \mathrm{C}, 20 \mathrm{~min}\right)$. Supernatants were analyzed by an LC-MS/MS system consisting of a Waters Alliance HT 2795 HPLC separation module coupled to a Waters Quattro Ultima Pt ESI tandem quadrupole mass spectrometer (Waters). The instrument was operated in negative electrospray ionization mode using MassLynx v. 4.0 software (Waters), and data processing was performed using QuanLynx software (Waters). For HPLC analysis, the Atlantis HILIC silica $3 \mu \mathrm{m} 2.1 \times 150 \mathrm{~mm}$ column (Waters) was used. Thirty $\mu \mathrm{L}$ of the extracted samples was injected onto the HPLC-MS/MS system. The technical replicate was performed. The mobile phase comprised a binary solvent system: acetonitrile (solvent A) and water containing $50 \mathrm{mmol} / \mathrm{L}$ ammonium acetate (solvent $\mathrm{B}$ ). The initial solvent composition was $100 \%$ A. $100 \%$ A was maintained for $3 \mathrm{~min}$, decreasing from the initial conditions to $50 \%$ A within $8.0 \mathrm{~min}$, holding for $4 \mathrm{~min}$ before returning to the initial state at 12.0 min, and allowing $4 \mathrm{~min}$ for column re-equilibration. The total run time was $16 \mathrm{~min}$, injection-to-injection. The flow rate was $0.3 \mathrm{~mL} / \mathrm{min}$. The mass spectrometer ionization source settings were optimized for maximum precursor ion yields for each metabolite. This was achieved by infusing a $1 \mu \mathrm{g} / \mathrm{mL}$ methanolic solution of each individual compound. ${ }^{47}$ The following transitions were monitored for the metabolites of interest: glucose 6-phosphate (G6P) $259.00>96.90$, cone $40 \mathrm{~V}$ and collision energy $13 \mathrm{eV}$; glyceraldehyde 3-phosphate (G3P) $168.90>96.90$, cone $40 \mathrm{~V}$ and collision energy $6 \mathrm{eV}$; phosphoenolpyruvate (PEP) $166.90>78.90$, cone $40 \mathrm{~V}$ and collision energy $7 \mathrm{eV}$; lactate (L) $89.00>43.00$, cone $40 \mathrm{~V}$ and collision energy $6 \mathrm{eV}$; malate $(\mathrm{M}) 133.00>115.00$, cone $40 \mathrm{~V}$ and collision energy $8 \mathrm{eV}$. The capillary voltage was $3.00 \mathrm{kV}$, source temperature was $100{ }^{\circ} \mathrm{C}$, desolvation temperature was $400{ }^{\circ} \mathrm{C}$, and collision cell gas pressure was $3.5 \times 10^{-3} \mathrm{mbar}$ argon. The interchannel and interscan delay times were 0.02 and $0.10 \mathrm{~s}$, respectively. The dwell time was $0.200 \mathrm{~s}$ for each analyte. The $P$ value was calculated by applying Student's $t$-test. $\mathrm{NADP}+/ \mathrm{NADPH}$ was determined in $10^{5}$ cell pellets, obtained as previously described, for each sample at $565 \mathrm{~nm}$ by an ultrasensitive colorimetric kit (EnzyChromTM NADP + NADPH Assay Kit, BioAssay Systems). $p$ value was calculated by applying Student's $t$-test.

Western Blotting

Transduced CSCs were collected by centrifugation at 1200 rpm. Cell pellets were washed twice with ice-cold PBS, resuspended in a $50 \mathrm{mM}$ Tris- $\mathrm{HCl}, \mathrm{pH} 7.5,150 \mathrm{mM} \mathrm{NaCl}, 1$ mM EDTA, $1 \mathrm{mM} \mathrm{NaF}, 10 \%$ glycerol, $1 \mathrm{mM} \mathrm{MgCl}, 1 \%$ Triton $\mathrm{X}-100$ ice-cold buffer containing proteinase inhibitor cocktail (Sigma-Aldrich), and incubated for $30^{\prime}$ on ice. Lysates were centrifuged at $10000 \mathrm{~g}$ for $10^{\prime}$ and supernatants were collected. $2.5 \mu \mathrm{g}$ of cell extracts were resolved on a $12 \%$ SDSpolyacrylamide gel using a mini-gel apparatus (Bio-Rad Laboratories). Western blots were performed as previously described $^{48}$ by using the following antibodies: anti-lactate dehydrogenase (PA5-27406, Thermo Scientific), anti-PKM2 (PA-23034, Thermo Scientific), anti-G6PD (PA5-27359, Thermo Scientific), anti-p63 (clone Y4A3, P3362, SigmaAldrich), anti- $\beta$-Actin (clone AC-15, A5441 Sigma-Aldrich).

\section{RESULTS}

\section{Quantitative Proteomics by Stable Isotope Dimethyl} Labeling and Functional Analysis of Modulated Proteins

To evaluate the effect of p63 isoforms expression on cellular processes, we employed a quantitative proteomic study. Colon CSCs derived from a primary tumor as previously described ${ }^{28}$ were transduced with lentiviral vectors carrying either TA or $\Delta \mathrm{Np} 63$. Prior to proteomic analysis, TAp63 $\alpha$ and $\Delta \mathrm{Np} 63 \alpha$ expression were evaluated in cell extracts obtained $48 \mathrm{~h}$ postinfection (Figure 1). Then, protein extracts of colon CSCs
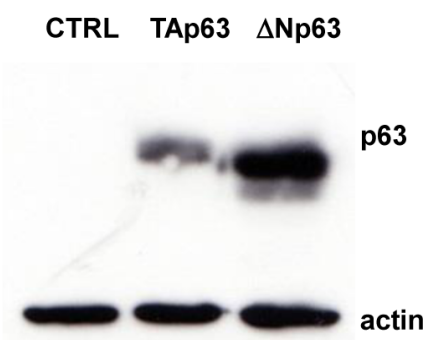

Figure 1. Evaluation of $\alpha \mathrm{p} 63$ expression $48 \mathrm{~h}$ postinfection. Representative experiment of Western blotting showing the level of TAp63 $\alpha$ and $\Delta \mathrm{Np} 63 \alpha$ expression after $48 \mathrm{~h}$ of infection. Actin was used as loading control.

transduced with empty vector, CTRL, and with vectors overexpressing TAp63 $\alpha$ or $\Delta \mathrm{Np} 63 \alpha$ were digested by trypsin prior reaction with dimethyl labels. We employed an off line 2D peptide separation strategy using IEF in the first step. The labeled samples were mixed and loaded on $18 \mathrm{~cm}$ immobiline dry strip, $\mathrm{pH} 3-10 \mathrm{NL}$, for peptides separation. The focused 
Table 1. List of Modulated Proteins Identified by Chemical Quantitative Analysis in TAp63 Cells with Respect to Control Cells

\begin{tabular}{|c|c|c|c|c|c|c|}
\hline $\operatorname{accession}^{a}$ & description $^{b}$ & score $^{c}$ & $\operatorname{mass}^{d}$ & TAp63/CTRL $^{e}$ & $\operatorname{SD}(\text { geo })^{f}$ & $\#^{g}$ \\
\hline AK1BA_HUMAN & aldo-keto reductase family 1 member $\mathrm{B} 10$ & 105 & 37283 & 0.35 & 1.05 & 2 \\
\hline AK1C1_HUMAN & aldo-keto reductase family 1 member $\mathrm{C} 1$ & 70 & 38055 & 0.35 & 1.01 & 2 \\
\hline HSP71 HUMAN & heat shock $70 \mathrm{kDa}$ protein $1 \mathrm{~A} / 1 \mathrm{~B}$ & $\underline{518}$ & $\underline{71696}$ & $\underline{0.36}$ & $\underline{1.36}$ & $\underline{6}$ \\
\hline METK2_HUMAN & $S$-adenosylmethionine synthase isoform type- 2 & 78 & 44841 & 0.4 & & 1 \\
\hline LEG4_HUMAN & galectin-4 & 268 & 36397 & 0.43 & & 1 \\
\hline CH10_HUMAN & $10 \mathrm{kDa}$ heat shock protein & $\underline{476}$ & $\underline{11233}$ & $\underline{0.49}$ & $\underline{1.54}$ & $\underline{5}$ \\
\hline CAPG_HUMAN & macrophage-capping protein & 86 & 39529 & 0.52 & & 1 \\
\hline NPM_HUMAN & nucleophosmin & 417 & 33651 & 0.52 & 1.44 & 3 \\
\hline EF1G_HUMAN & elongation factor 1-gamma & 282 & 51455 & 0.53 & & 1 \\
\hline IPYR_HUMAN & inorganic pyrophosphatase & 140 & 33880 & 0.53 & & 1 \\
\hline KCRB_HUMAN & creatine kinase B-type & 302 & 43491 & 0.54 & 1.13 & 2 \\
\hline CH60_HUMAN & $60 \mathrm{kDa}$ heat shock protein & $\underline{1432}$ & $\underline{62886}$ & $\underline{0.6}$ & $\underline{1.10}$ & $\underline{9}$ \\
\hline$\overline{\mathrm{ECH} 1 \text { HUMAN }}$ & $\overline{\operatorname{delta}(3,5)-\operatorname{delta}(2,4) \text {-dienoyl-CoA isomerase }}$ & 300 & 36612 & 0.6 & & 1 \\
\hline ETFA_HUMAN & electron transfer flavoprotein subunit alpha & 162 & 36129 & 0.6 & & 1 \\
\hline UGDH_HUMAN & UDP-glucose 6-dehydrogenase & $\underline{648}$ & $\underline{56683}$ & $\underline{0.6}$ & $\underline{1.12}$ & $\underline{5}$ \\
\hline PRDX1_HUMAN & peroxiredoxin-1 & 298 & 22857 & 0.61 & & 1 \\
\hline HSPB1_HUMAN & heat shock protein beta- 1 & 586 & 23022 & 0.62 & 1.08 & 5 \\
\hline MDHM_HUMAN & malate dehydrogenase & $\underline{702}$ & $\underline{36666}$ & $\underline{0.62}$ & $\underline{1.19}$ & $\underline{8}$ \\
\hline ECHM_HUMAN & $\overline{\text { enoyl-CoA hydratase }}$ & 169 & 32496 & 0.63 & & 1 \\
\hline H33_HUMAN & histone $\mathrm{H} 3.3$ & 122 & 15740 & 0.63 & 1.32 & 4 \\
\hline IF4A1_HUMAN & eukaryotic initiation factor 4A-I & 132 & 46913 & 0.63 & 1.25 & 2 \\
\hline K1C19_HUMAN & keratin, type I cytoskeletal 19 & 678 & 44472 & 0.63 & 1.13 & 5 \\
\hline TKT_HUMAN & transketolase & $\underline{581}$ & $\underline{69696}$ & $\underline{0.63}$ & $\underline{1.07}$ & $\underline{7}$ \\
\hline HNRPQ HUMAN & heterogeneous nuclear ribonucleoprotein $\mathrm{Q}$ & $\overline{61}$ & $\overline{71077}$ & $\overline{0.67}$ & & 1 \\
\hline ADT2_HUMAN & $\mathrm{ADP} / \mathrm{ATP}$ translocase 2 & 341 & 33704 & 0.68 & 1.42 & 4 \\
\hline HNRPK_HUMAN & heterogeneous nuclear ribonucleoprotein $\mathrm{K}$ & 554 & 51846 & 0.68 & 1.12 & 4 \\
\hline GRP75_HUMAN & stress-70 protein & 659 & 75378 & 0.69 & 1.27 & 3 \\
\hline AGR2_HUMAN & anterior gradient protein 2 homologue & 106 & 20528 & 0.69 & 1.48 & 3 \\
\hline DHSA_HUMAN & succinate dehydrogenase & 317 & 74485 & 0.69 & 1.32 & 2 \\
\hline HSP7C_HUMAN & heat shock cognate $71 \mathrm{kDa}$ protein & 1004 & 72596 & 0.69 & 1.33 & 7 \\
\hline LMNA_HUMAN & prelamin-A/C & 487 & 75501 & 0.69 & 1.38 & 6 \\
\hline H2A2A_HUMAN & histone $\mathrm{H} 2 \mathrm{~A}$ type 2-A & 769 & 14479 & 1.32 & 1.23 & 10 \\
\hline SERA_HUMAN & D-3-phosphoglycerate dehydrogenase & 46 & 58189 & 1.33 & & 1 \\
\hline PPIB_HUMAN & peptidyl-prolyl cis-trans isomerase $\mathrm{B}$ & 164 & 24513 & 1.35 & 1.30 & 4 \\
\hline 1433T_HUMAN & $14-3-3$ protein theta & 347 & 28564 & 1.36 & & 1 \\
\hline TCPD_HUMAN & T-complex protein 1 subunit delta & 173 & 59494 & 1.36 & 1.12 & 2 \\
\hline FLNA_HUMAN & filamin-A & 553 & 287786 & 1.43 & & 1 \\
\hline GANAB_HUMAN & neutral alpha-glucosidase $A B$ & 219 & 108128 & 1.45 & 1.10 & 2 \\
\hline TBB5_HUMAN & tubulin beta chain & 993 & 50576 & 1.48 & & 1 \\
\hline PUR6_HUMAN & multifunctional protein $\mathrm{ADE} 2$ & 138 & 48772 & 1.48 & & 1 \\
\hline WDR1_HUMAN & WD repeat-containing protein 1 & 110 & 67957 & 1.51 & & 1 \\
\hline IQGA1_HUMAN & Ras GTPase-activating-like protein & 142 & 194057 & 1.52 & & 1 \\
\hline RLA1_HUMAN & $60 S$ acidic ribosomal protein $\mathrm{P} 1$ & 144 & 11845 & 1.54 & & 1 \\
\hline SPTN1_HUMAN & spectrin alpha chain & 275 & 290713 & 1.63 & & 1 \\
\hline H2B1C_HUMAN & histone $\mathrm{H} 2 \mathrm{~B}$ type $1-\mathrm{C} / \mathrm{E} / \mathrm{F} / \mathrm{G} / \mathrm{I}$ & 358 & 14458 & 1.65 & & 1 \\
\hline UBA1_HUMAN & ubiquitin-like modifier-activating enzyme 1 & 440 & 120343 & 1.69 & & 1 \\
\hline HNRPL_HUMAN & heterogeneous nuclear ribonucleoprotein $\mathrm{L}$ & 124 & 65533 & 1.71 & & 1 \\
\hline DHX9_HUMAN & ATP-dependent RNA helicase A & 174 & 144264 & 1.85 & & 1 \\
\hline RS10_HUMAN & $40 S$ ribosomal protein $S 10$ & 68 & 19250 & 2.44 & & 1 \\
\hline NDUAD_HUMAN & NADH dehydrogenase [ubiquinone] 1 & 58 & 16880 & 3.52 & & 1 \\
\hline CSPG4_HUMAN & chondroitin sulfate proteoglycan & 104 & 251996 & 4.54 & & 1 \\
\hline
\end{tabular}

${ }^{a}$ ID protein according to SwissProt database. ${ }^{b}$ Protein description. ${ }^{c}$ Mascot score. Only proteins identified with score $>40$ were reported. ${ }^{d}$ Protein mass. ${ }^{e}$ Protein ratio TAp63/CTRL, expressed as median. Only proteins with a ratio $>1.3$ and $<0.7$ are reported. ${ }^{f}$ SD $($ geo) $)=$ geometric standard deviation calculated by Distiller; when absent the number of peptides was insufficient to calculate it. ${ }^{g}$ Number of peptides used for quantitation. Underlined proteins indicated proteins validated in targeted label free experiment.

strips were cut in several pieces, and extracted peptides were analyzed by $\mathrm{nLC}-\mathrm{MS} / \mathrm{MS}$ for protein identification and quantification. The list of proteins modulated after TAp63 overexpression is reported in Table 1 (See Table $2 S$ in the
Supporting Information for peptide identification details). A total of 51 proteins were found differentially regulated with ratio above 1.3 or below 0.7 , with peptides satisfying the quality parameters reported in the Experimental Section (Figure 2). 


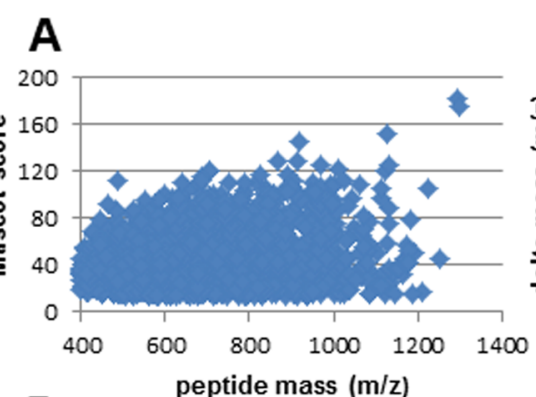

D

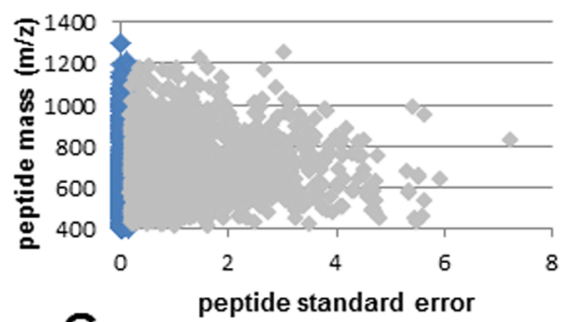

G
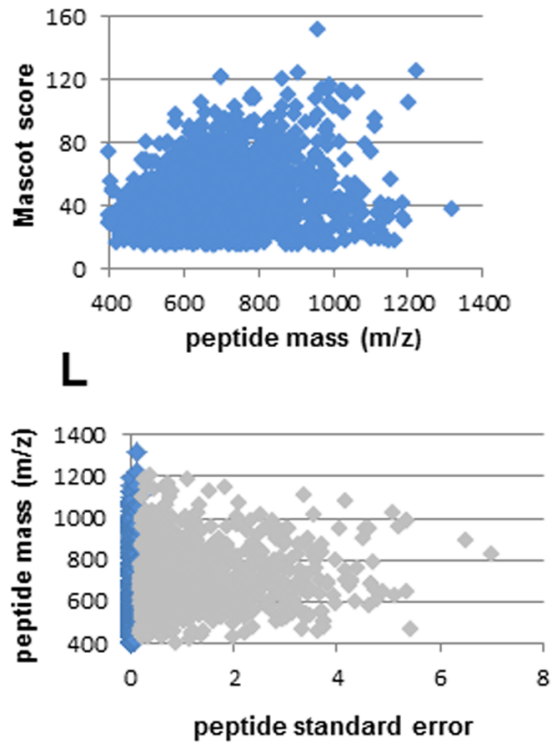

B

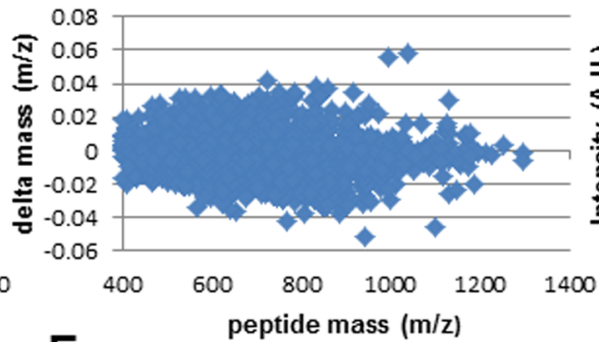

E

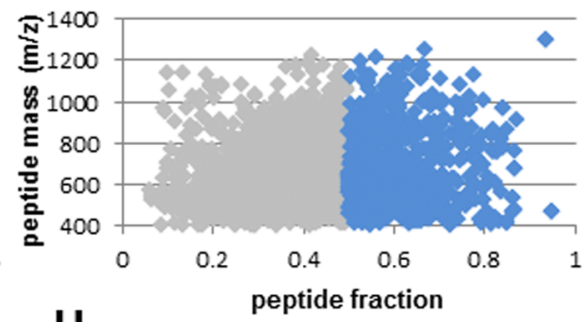

H
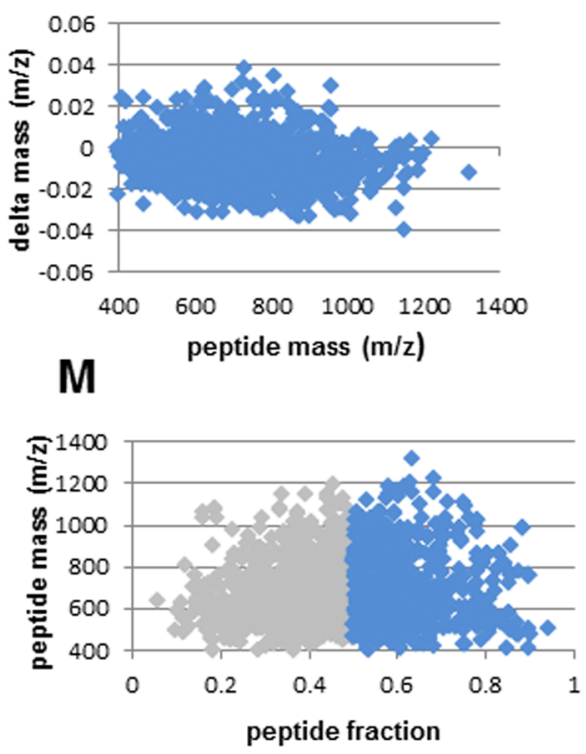

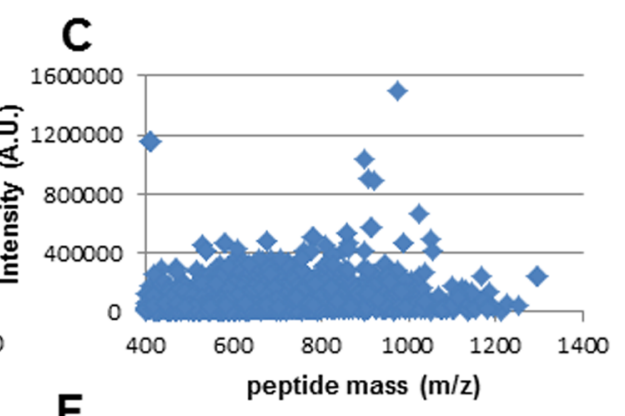

F
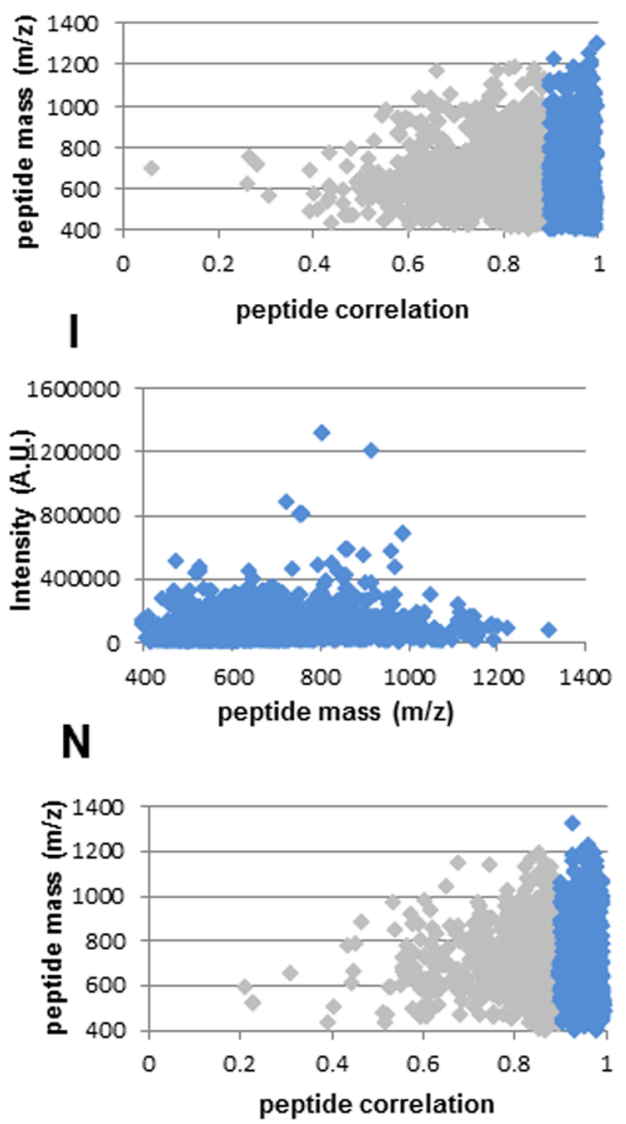

Figure 2. Peptides data quality evaluation for TAp63 (A-F) and $\Delta$ Np63 (G-H) data sets. Bar charts showing peptide identification results: Mascot score $(A, G)$, experimental mass error $(B, H)$, and intensity distribution $(\mathrm{C}, \mathrm{I})$. Moreover quality parameters for peak detection are displayed: Standard error $(D, L)$, fraction $(E, M)$, and correlation $(F, N)$. (See the Experimental Section for more details.) Gray points represent discarded peptides.

Reported proteins were identified with Mascot score above 40 and FDR $<1 \%$. In the case of $\Delta \mathrm{Np} 63$ transfected cells, after data processing and database search a total of 38 proteins were found modulated with ratio above 1.3 or below 0.7 , whose peptides satisfied the quality parameters reported in the Experimental Section (Figure 2). All reported proteins were identified with Mascot score above 40 and FDR $<1 \%$ (Table 2 and Table $3 S$ in the Supporting Information).

Proteins listed in Tables 1 and 2 were used as input files for PANTHER Classification System to classify the biological processes regulated by the proteins modulated in TAp63 and $\Delta \mathrm{Np} 63$ data set, respectively (Figure 3 ). As shown in pie charts, apoptosis is the discriminating biological process between the two data sets. NAD-dehydrogenase (NDUAD, GRIM-19), annotated as apoptotic inducers in Panther database, was found to be up-regulated in TAp63 overexpressing cells, whereas galectin-4 (LEG4) and heterogeneous nuclear ribonucleoprotein $\mathrm{K}$ (HNRPK), also associated with induction of apoptosis process, were found down-regulated. Interestingly, in both data sets a great part of the modulated proteins was involved in metabolic process, representing 35.1 and $30.3 \%$ of the pie chart in TAp63 and $\Delta \mathrm{Np} 63$ experiments, respectively. Moreover, in both cases, proteins associated with the generation of precursor metabolites and energy were highlighted, underlining the possible involvement of both p63 isoforms in regulating cancer cells metabolism. Proteins included in this biological process were found to be downregulated after transfection with TAp63 expressing vector. They were: UDP-glucose 6-dehydrogenase (UGDH) involved in biosynthesis of glycosaminoglycans, mitochondrial succinate dehydrogenase (DHSA) and mitochondrial malate dehydrogenase (MDHM) belonging to tricarboxylic acid (TCA) cycle, and mitochondrial electron transfer flavoprotein subunit alpha (ETFA), which transfers electrons to the main mitochondrial respiratory chain. In the $\Delta \mathrm{Np} 63$ data set, proteins associated with this biological process, ATP-citrate synthase (ACLY) and 
Table 2. List of Modulated Proteins Identified by Chemical Quantitative Analysis in $\Delta$ Np63 Cells with Respect to Control Cells

\begin{tabular}{|c|c|c|c|c|c|c|}
\hline accession $^{a}$ & description $^{b}$ & score $^{c}$ & $\operatorname{mass}^{d}$ & $\Delta \mathrm{Np} 63 / \mathrm{CTRL}^{e}$ & $\operatorname{SD}(\text { geo })^{f}$ & $\#^{g}$ \\
\hline CLIC1_HUMAN & chloride intracellular channel protein 1 & 137 & 27825 & 0.21 & & 1 \\
\hline HSP71_HUMAN & heat shock $70 \mathrm{kDa}$ protein $1 \mathrm{~A} / 1 \mathrm{~B}$ & $\underline{577}$ & $\underline{71696}$ & $\underline{0.36}$ & & $\underline{1}$ \\
\hline AK1BA_HUMAN & aldo-keto reductase family 1 & 76 & 37150 & 0.46 & & 1 \\
\hline MIF_HUMAN & macrophage migration inhibitory factor & 42 & 12735 & 0.48 & & 1 \\
\hline S100P_HUMAN & protein $\mathrm{S} 100-\mathrm{P}$ & 52 & 10731 & 0.53 & & 1 \\
\hline PTBP1_HUMAN & polypyrimidine tract-binding protein 1 & 233 & 58282 & 0.60 & 1.35 & 3 \\
\hline EZRI_HUMAN & ezrin & 58 & 71247 & 0.62 & & 1 \\
\hline METK2_HUMAN & $S$-adenosylmethionine synthase & 46 & 44732 & 0.64 & & 1 \\
\hline RL30_HUMAN & $60 S$ ribosomal protein $\mathrm{L} 30$ & 136 & 13396 & 0.66 & & 1 \\
\hline CH10 HUMAN & $10 \mathrm{kDa}$ heat shock protein & $\underline{280}$ & $\underline{11277}$ & $\underline{0.67}$ & $\underline{1.43}$ & $\underline{5}$ \\
\hline G6PI HUMAN & glucose-6-phosphate isomerase & $\underline{424}$ & $\underline{64316}$ & $\underline{0.68}$ & $\underline{1.10}$ & $\underline{4}$ \\
\hline RL5_HUMAN & $60 \mathrm{~S}$ ribosomal protein L5 & 88 & 35550 & 0.69 & & 1 \\
\hline KCRB_HUMAN & creatine kinase B-type & 179 & 43491 & 0.70 & & 1 \\
\hline FAS_HUMAN & fatty acid synthase & 696 & 278602 & 1.30 & 1.03 & 5 \\
\hline GSTP1_HUMAN & glutathione $S$-transferase $\mathrm{P}$ & 128 & 23905 & 1.31 & 1.35 & 3 \\
\hline ARP3B_HUMAN & actin-related protein $3 \mathrm{~B}$ & 51 & 48764 & 1.32 & & 1 \\
\hline ACTN4_HUMAN & $\underline{\text { alpha-actinin-4 }}$ & $\underline{515}$ & $\underline{106870}$ & $\underline{1.32}$ & & $\underline{1}$ \\
\hline MDHC_HUMAN & $\overline{\text { malate dehydrogenase }}$ & 139 & 37500 & 1.39 & & 1 \\
\hline LPPRC_HUMAN & leucine-rich PPR motif-containing protein & 60 & 162272 & 1.40 & & 1 \\
\hline SAHH_HUMAN & adenosylhomocysteinase & 62 & 49185 & 1.40 & & 1 \\
\hline HNRPF_HUMAN & heterogeneous nuclear ribonucleoprotein $\mathrm{F}$ & 149 & 46433 & 1.40 & & 1 \\
\hline HYOU1_HUMAN & hypoxia up-regulated protein 1 & 232 & 113963 & 1.42 & & 1 \\
\hline PPIB_HUMAN & peptidyl-prolyl cis-trans isomerase B & 93 & 24618 & 1.42 & & 1 \\
\hline ACLY_HUMAN & ATP-citrate synthase & 47 & 123982 & 1.42 & & 1 \\
\hline ANXA5_HUMAN & annexin A5 & 159 & 36677 & 1.43 & & 1 \\
\hline RS14_HUMAN & 40S ribosomal protein $\mathrm{S} 14$ & 48 & 16867 & 1.52 & & 1 \\
\hline$\underline{\text { K1C18 HUMAN }}$ & keratin, type I cytoskeletal 18 & $\underline{487}$ & $\underline{48617}$ & $\underline{1.53}$ & $\underline{1.39}$ & $\underline{6}$ \\
\hline IPYR_HUMAN & $\overline{\text { inorganic pyrophosphatase }}$ & 76 & 33993 & 1.62 & & 1 \\
\hline CALX_HUMAN & calnexin & 128 & 69524 & 1.62 & & 1 \\
\hline HSP74_HUMAN & heat shock $70 \mathrm{kDa}$ protein 4 & 84 & 97723 & 1.63 & & 1 \\
\hline K1C19_HUMAN & Keratin, type I cytoskeletal 19 & 302 & 44472 & 1.69 & & 1 \\
\hline WDR1_HUMAN & WD repeat-containing protein 1 & 61 & 68118 & 1.86 & & 1 \\
\hline EF1D_HUMAN & elongation factor 1 -delta & 70 & 31777 & 1.90 & & 1 \\
\hline PELP1_HUMAN & proline-, glutamic acid-, and leucine-rich protein 1 & 48 & 121440 & 1.95 & & 1 \\
\hline MATR3_HUMAN & matrin-3 & 53 & 96928 & 2.12 & & 1 \\
\hline HSP7C_HUMAN & heat shock cognate $71 \mathrm{kDa}$ & 536 & 72596 & 2.16 & & 1 \\
\hline CSPG4_HUMAN & chondroitin sulfate proteoglycan 4 & 192 & 251880 & 2.22 & 1.24 & 2 \\
\hline
\end{tabular}

${ }^{a} \mathrm{ID}$ protein according to SwissProt database. ${ }^{b}$ Protein description. ${ }^{c}$ Mascot score. Only protein identified with score $>40$ were reported. ${ }^{d}$ Protein mass. ${ }^{e}$ Protein ratio $\Delta \mathrm{Np} 63 / \mathrm{CTRL}$, expressed as median. Only protein with a ratio $>1.3$ and $<0.7$ are reported. ${ }^{f_{\mathrm{SD}}}$ (geo) $=$ geometric standard deviation calculated by Distiller; when absent the number of peptides was insufficient to calculate it. ${ }^{g}$ Number of peptides used for quantitation. Underlined proteins indicated proteins validated in targeted label free experiment.

\section{A}

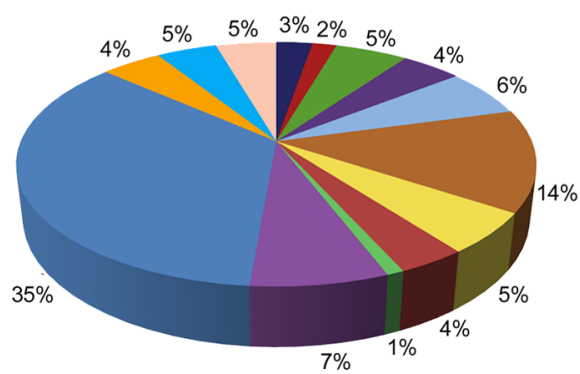

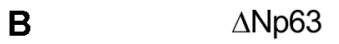

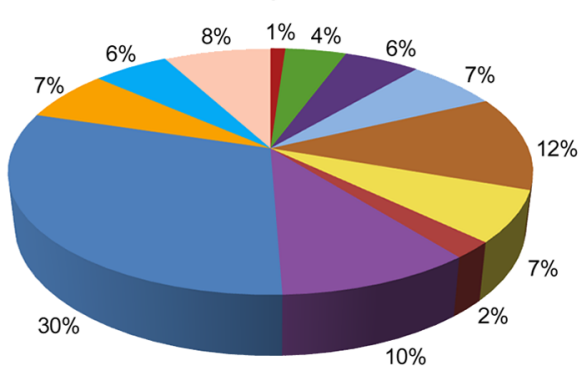

apoptosis

cell adhesion

cell communication

cell cycle

celular component organization

cellular process

developmental process

generation of precursor metabolites and energy

homeostatic process

immune system process

metabolic process

response to stimulus

system process

transport

Figure 3. Functional analysis by PANTHER classification system. Pie charts showing biological processes of modulated proteins found in TAp63 (A) and $\Delta \mathrm{Np} 63(\mathrm{~B})$.

cytoplasmic malate dehydrogenase (MDHC), were found to be up-regulated in transfected cells. In mitochondria, ACLY uses acetyl-CoA and oxaloacetate to produce citrate, which is transported to the cytosol. Here citrate is used by citrate lyase to generate acetyl-CoA, while the resulting oxaloacetate is converted to malate by cytoplasmic $\mathrm{MDH}$, thus producing NADPH. The observed modulation of both ACLY and cytoplasmic $\mathrm{MDH}$ suggested an increased production of 
acetyl-CoA, which can be used in lipid synthesis. Moreover fatty acid synthetase (FAS) was found to be up-regulated in $\Delta \mathrm{Np} 63$ expressing cells.

Molecular and cellular functions were investigated also by Ingenuity Pathway Analysis software (IPA) (Table 3). Results

Table 3. Ingenuity Pathway Analysis Results: List of Significant Molecular and Cellular Function

\begin{tabular}{|c|c|c|}
\hline molecular and cellular function & $p$ value & $\begin{array}{c}\text { no. of } \\
\text { molecules }\end{array}$ \\
\hline \multicolumn{3}{|l|}{ TAp63 Experiment } \\
\hline $\begin{array}{l}\text { cellular assembly and } \\
\text { organization }\end{array}$ & $\begin{array}{c}3.06 \times 10^{-6} \text { to } \\
4.73 \times 10^{-2}\end{array}$ & 15 \\
\hline energy production & $\begin{array}{l}8.94 \times 10^{-6} \text { to } \\
2.10 \times 10^{-2}\end{array}$ & 7 \\
\hline nucleic acid metabolism & $\begin{array}{l}8.94 \times 10^{-6} \text { to } \\
3.28 \times 10^{-2}\end{array}$ & 11 \\
\hline small-molecule metabolism & $\begin{array}{l}8.94 \times 10^{-6} \text { to } \\
4.62 \times 10^{-2}\end{array}$ & 20 \\
\hline post-translational modification & $\begin{array}{c}8.87 \times 10^{-5} \text { to } \\
2.69 \times 10^{-2}\end{array}$ & 8 \\
\hline \multicolumn{3}{|l|}{$\Delta$ Np63 Experiment } \\
\hline cell death and survival & $\begin{array}{c}6.45 \times 10^{-6} \text { to } \\
4.05 \times 10^{-2}\end{array}$ & 21 \\
\hline $\begin{array}{l}\text { cellular function and } \\
\text { maintenance }\end{array}$ & $\begin{array}{c}8.73 \times 10^{-5} \text { to } \\
4.16 \times 10^{-2}\end{array}$ & 13 \\
\hline cell cycle & $\begin{array}{l}1.79 \times 10^{-4} \text { to } \\
4.78 \times 10^{-2}\end{array}$ & 13 \\
\hline cell morphology & $\begin{array}{c}1.79 \times 10^{-4} \text { to } \\
4.29 \times 10^{-2}\end{array}$ & 10 \\
\hline $\begin{array}{l}\text { cellular assembly and } \\
\text { organization }\end{array}$ & $\begin{array}{c}1.79 \times 10^{-4} \text { to } \\
4.04 \times 10^{-2}\end{array}$ & 16 \\
\hline
\end{tabular}

emphasized the perturbation of metabolic process and process associated with cellular assembly and organization in TAp63 experiment and cell death and survival, cellular function and maintenance, cell cycle, cell morphology, and cellular assembly and organization in $\Delta \mathrm{Np} 63$ experiment.

Performing functional annotation cluster by DAVID in TAp63 data set, functions associated with stress response and protein folding were enriched in cluster 1 with a score of 3.55 (Table $4 \mathrm{~S}$ in the Supporting Information). Interestingly the second ranked cluster was prevalently associated with mitochondrion and organelle lumen (enrichment score $=$ 3.19), thus indicating alterations of mitochondrial processes after TAp63 expression. In particular, $\mathrm{NADH}$ dehydrogenase (NDUAD), creatine kinase (KKRB), ETFA, enoyl coenzyme A hydratase (ECHM), four heat shock proteins ( $\mathrm{CH} 10, \mathrm{CH} 60$, HSP71, and GRP75), MDHM, peroxiredoxin 1 (PRDX1), solute carrier family 25 (ADT2, ADP/ATP translocase 2), and DHSA were associated with mitochondrion in cluster 2 . Submitting $\Delta \mathrm{Np} 63$ data set to DAVID, the enriched Cluster 1 , with score of 2.83 , was mostly composed of proteins associated with stress response, heat shock proteins, ATP, or nucleoside binding, indicating the modulation of energy metabolism and nucleic acid metabolism after $\Delta \mathrm{Np} 63$ expression (Table 5S in the Supporting Information).

To investigate TAp63- and $\Delta \mathrm{Np} 63$-mediated cellular signaling, we performed an unsupervised bioinformatics analysis using IPA. Known mutual interactions among differentially expressed proteins were used to construct protein networks ranked by score (Table 4). In the TAp63 experiment, the network generated with higher score and associated with energy production, nucleic acid metabolism, and small molecule biochemistry functions (Figure 4A) was constructed by some of
Table 4. Ingenuity Pathway Analysis Results: List of Significant Networks

\begin{tabular}{llc}
\multicolumn{1}{c}{ network } & \multicolumn{1}{c}{ associated network functions } & score \\
$\begin{array}{l}\text { TAp63 } \\
1\end{array}$ & 58 \\
2 & $\begin{array}{l}\text { experiment } \\
\text { molecule biochemistry } \\
\text { developmental disorder, hereditary disorder, metabolic } \\
\text { disease }\end{array}$ & 29 \\
3 & $\begin{array}{l}\text { tissue morphology, cell morphology, hematological } \\
\text { system development and function }\end{array}$ & 21 \\
$\begin{array}{l}\text { Exp63 } \\
1\end{array}$ & $\begin{array}{l}\text { cancer, tumor morphology, cell death and survival } \\
2\end{array}$ & 51 \\
3 & $\begin{array}{l}\text { RNA post-transcriptional modification, post- } \\
\text { translational modification, carbohydrate metabolism } \\
\text { hematological disease, hereditary disorder, tissue } \\
\text { morphology }\end{array}$ & 27 \\
\hline
\end{tabular}

the already cited proteins, such as heat shock proteins, CKRB, ECHM, MDHM, PRDX1, ADT2 (SLC25A5), and UGDH. The main nodes deduced by IPA were represented by Akt and MAPK1/2, which are known to be essential for glucose homeostasis. ${ }^{49}$ Network with higher score in $\Delta$ Np63 experiment was associated with cancer, tumor morphology, cell death, and survival (Figure 2B). Relevant modulated proteins of this network were: heat shock proteins, structural proteins such as keratins (K1C18), actinin 4 (ACTN4), and actin-binding protein, which is associated with cell motility and cancer metastasis, ${ }^{50}$ ezrin (EZR), involved in maintaining the cell cortex $^{51}$ and enzymes, such as CKRB and glucose-6-phosphate isomerase (G6PI, GPI in the network). Interestingly, the main node of the network deduced by the software was Akt, thus underlining similarity with TAp63. Similarly to TAp63, metabolism was also reported as a relevant network function, although with lower score $($ score $=27)$, associated with carbohydrate metabolism, RNA post-transcriptional modification, and post-translational modification in network 2 (Table 3 ). In silico analysis allowed us to highlight also possible upstream regulators of the reported networks. In both TAp63 and $\Delta \mathrm{Np} 63$ experiment, Myc was predicted to be modulated with significant score (Figure 5A). Moreover, in the case of $\Delta \mathrm{Np} 63$ in addition to Myc, also p53 was predicted to be modulated (Figure 5B).

\section{Targeted Label-Free Quantitative Analysis}

To validate experimental evidence found by quantitative labeled proteomic investigation followed by in silico functional analysis, we carried out a targeted label-free strategy to quantify the proteotypic peptides of regulated proteins of interest. Whole protein extracts of CTRL, TAp63, and $\Delta$ Np63-transfected cells were digested by trypsin and loaded on a nanoACQUITY UPLC system coupled to a Q-TOF mass spectrometer operating in high-low mode. Triplicates were run for each condition. Raw data were first analyzed to evaluate chromatographic reproducibility and processed by PLGS software, using SwissProt database restricted to Homo sapiens taxonomy, to evaluate the number of total identified proteins. (Representative protein lists identified in a single run of each condition, with FPR $<1 \%$, are reported in Table $6 \mathrm{~S}$ in the Supporting Information.) The EMRT (exact mass retention time) peptide clusters, that is, the list of paired exact masses and retention times ${ }^{42-44}$ found by the software, showed RSD (relative standard deviation) mass below $15 \mathrm{ppm}$ and \%CV RT (coefficient variation on retention time) mostly below 6\%, 

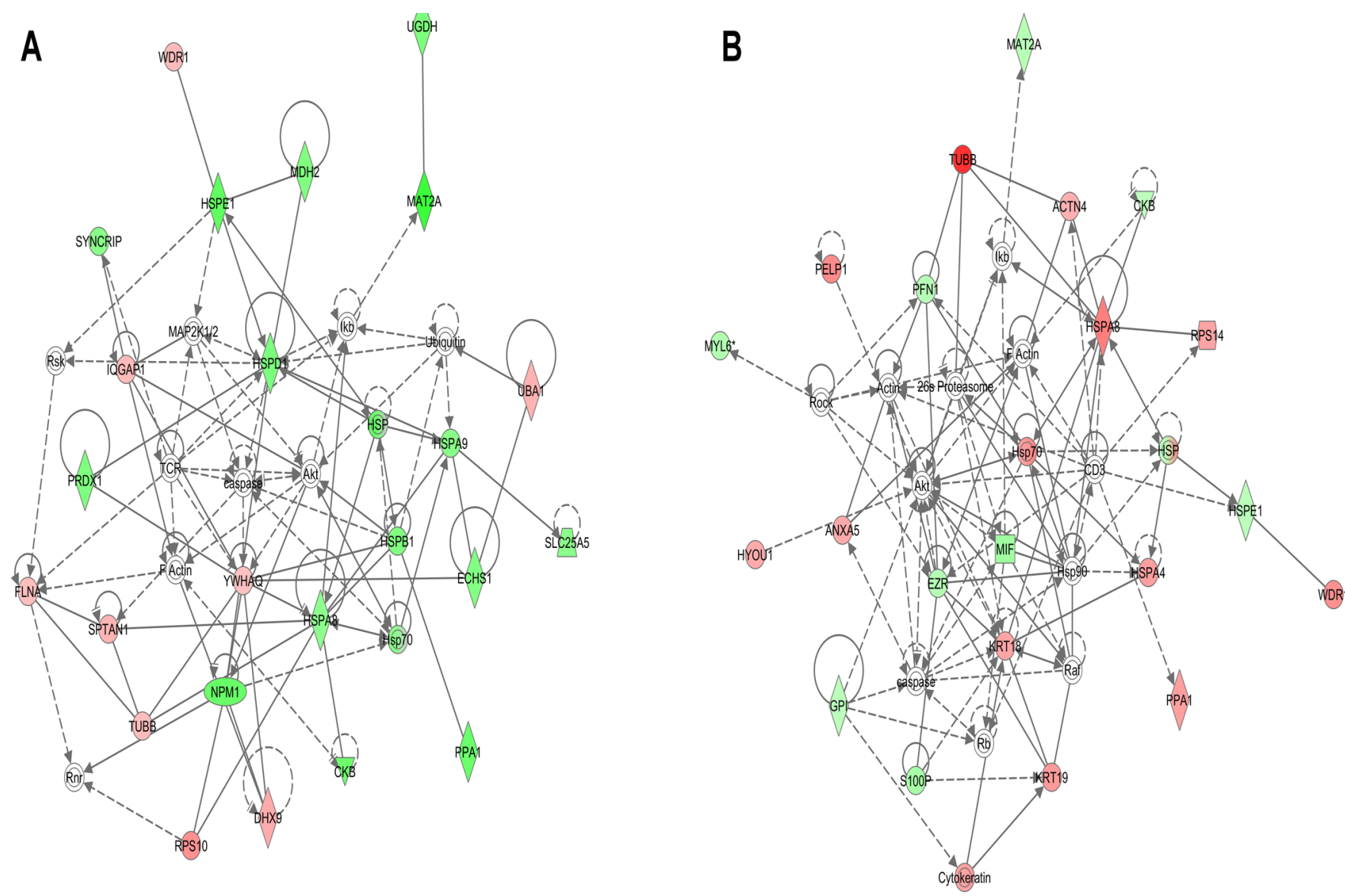

Figure 4. Pathway analysis. (A) Network generated for TAp63 experiment, showing score $=58$, was involved in energy production, nucleic acid metabolism, and small-molecule biochemistry. (B) Network with higher score in $\Delta \mathrm{Np} 63$ experiment was associated with cancer, tumor morphology, cell death, and survival. Nodes represent proteins: shaded features describe proteins identified in the present study (red, up-regulated; green, downregulated), whereas unshaded features describe additional members deduced by the software.
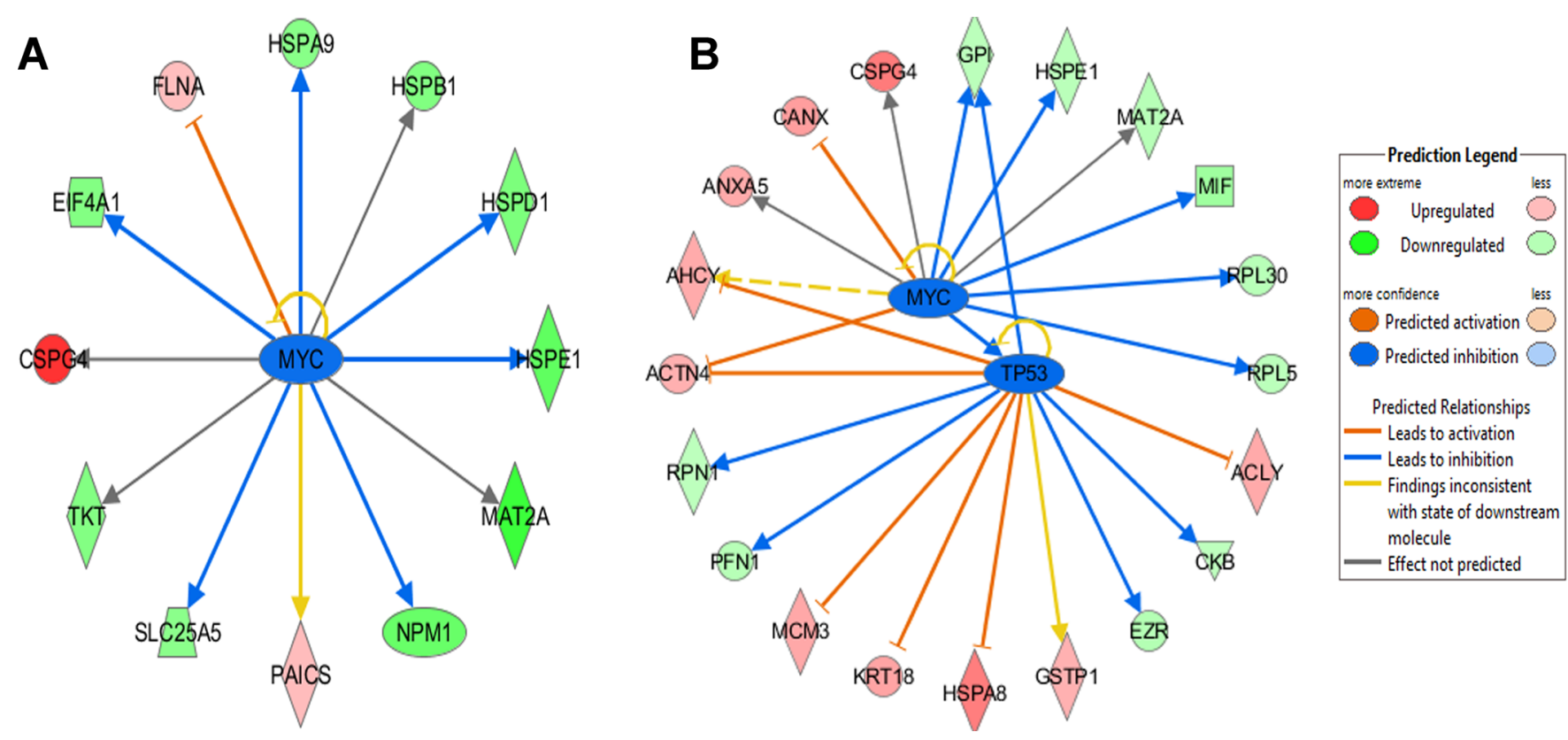

Figure 5. Upstream regulators predicted by in silico analysis. In TAp63, Myc was predicted to be modulated with significant $p$ value $=3.07 \times 10^{-7}$ (A), while in $\Delta$ Np63 experiment, Myc and p53 were predicted to be modulated, $p$ value $=4.23 \times 10^{-7}$ and $3.65 \times 10^{-6}(\mathrm{~B})$.

and \%CV intensity (coefficient variation of EMRTs intensities) showed Gaussian distributions centered on mean value of $2 \%$
$\mathrm{CV}$ under the three conditions (Figure 1S in the Supporting Information). Raw data were then used to generate extracted 


\section{A Targeted label free analysis}

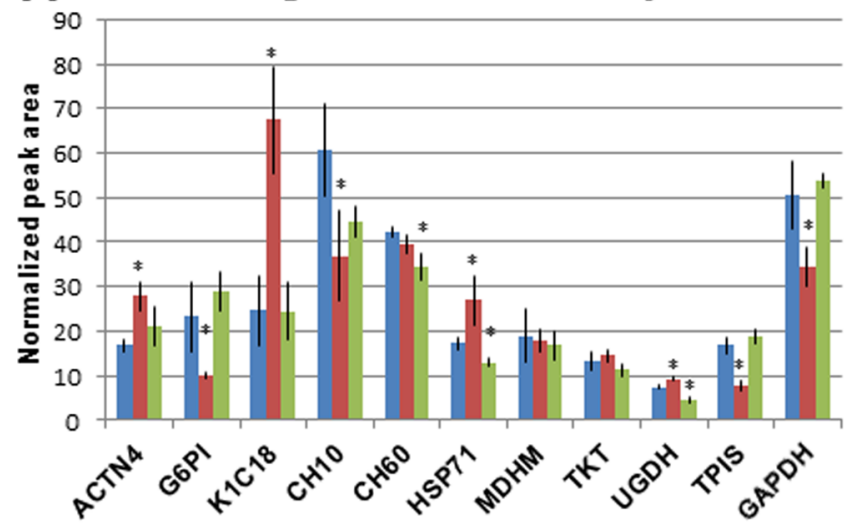

\section{B Targeted metabolomic analysis}

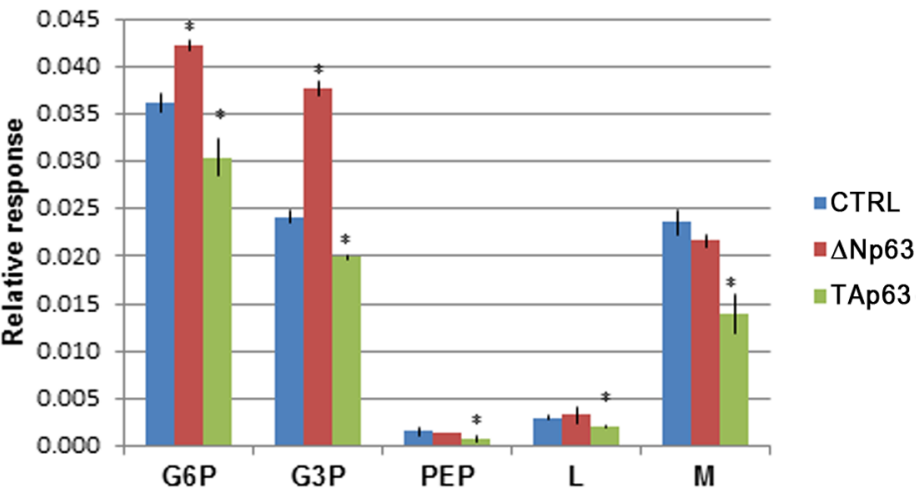

C

CTRL TAp63 $\Delta$ Np63
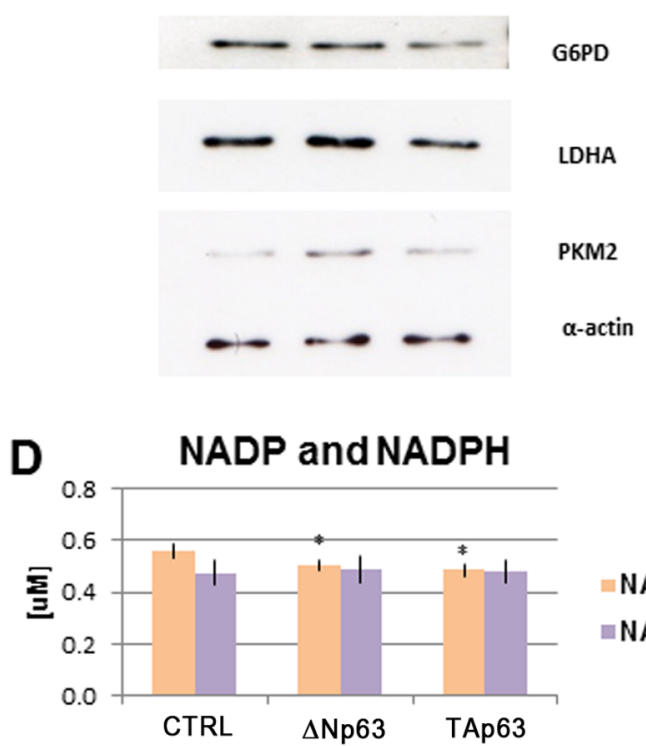

$=$ NADP

$\because \mathrm{NADPH}$

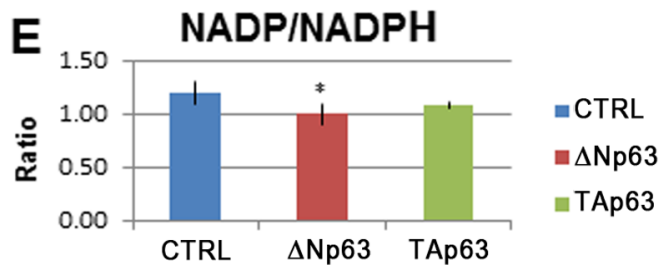

Figure 6. (A) Targeted proteomic analysis. LC-MS/MS runs of unlabeled samples were processed by Skyline software to quantify proteotypic peptides of interesting proteins. ACTN4, alpha actinin 4; CH10, $10 \mathrm{kDa}$ heat shock protein, mitochondrial; CH60, $60 \mathrm{kDa}$ heat shock protein, mitochondrial; HSP71, heat shock $70 \mathrm{kDa}$ protein 1A/1B; G6PI, glucose-6-phosphate isomerase; TPIS, triosephosphate isomerase; GAPDH, glyceraldehyde-3-phosphate dehydrogenase; cytoskeletal keratin-18 (K1C18); mitochondrial malate dehydrogenase (MDHM), UDP-glucose 6dehydrogenase (UGDH). Protein abundance is reported as peaks area generated by XIC after normalization. Endogenous actin was used as standard for normalization. Error bars represent standard deviation calculated on three different analytical runs. Asterisks indicate statistical significance $(t$ test $p$ value $<0.05$ for TAp63 or $\Delta$ Np63 cells vs control cells). More details are reported in Table 5. (B) Targeted metabolomics analysis. Metabolites were extracted from CTRL, TAp63, and $\Delta \mathrm{Np63}$ cells. Glucose 6-phosphate (G6P), glyceraldehyde 3-phosphate (G3P), phosphoenolpyruvate (PEP), lactate (L), and malate (M) were determined by mass spectrometry and reported as relative response (arbitrary units, calculated as the peak area of each analyte normalized to the total chromatographic peak areas). Error bars represent standard deviation calculated on three different analytical runs. Asterisks indicate statistical significance ( $p$ value $<0.05 t$ test of TAp63 or $\Delta$ Np63 cells vs control cells.) (C) Immunoblotting analysis. Western-blotting analysis was carried out using whole cell lysate from CTRL, TAp63, and $\triangle$ Np63 cells and antibodies against LDHA (lactate dehydrogenase A chain), G6PD (glucose-6-phosphate 1-dehydrogenase), and PKM2 (pyruvate kinase). Actin was used as loading control. (D) Measurement of NADP and NADPH. Asterisks indicate statistical significance ( $p$ value $<0.05 t$ test of TAp63 or $\Delta$ Np63 cells vs control cells). (E) Determination of NADP/NADPH ratio. Asterisks indicate statistical significance ( $p$ value $<0.05 t$ test of TAp63 or $\Delta$ Np63 cells vs control cells).

ion chromatograms (XICs) by Skyline software. XIC traces of MS1 traces were used for integrating peak area and determining the abundance of proteotypic peptides of interesting proteins with respect to actin proteotypic peptides, used for normalization. The following proteins were included in this investigation: mitochondrial heat shock proteins (HSP10, HSP60, and HSP71), alpha actinin 4 (ACTN4), cytokeratin18 (K1C18), and some metabolic enzymes, such as glucose-6phosphate isomerase (G6PI), mitochondrial malate dehydrogenase (MDHM), UDP-glucose 6-dehydrogenase (UGDH), triosephosphate isomerase (TPIS), glyceraldehyde-3-phosphate dehydrogenase (GAPDH), and transketolase (TKT) (Figure 6A. Proteins were quantified using two proteotypic peptides (with the exception of CH10, HSP71, and UGDH), with a percentage of coefficient of variation $(\% \mathrm{CV})$ for peptide retention times (RTs) below 5\% and a \%CV calculated for normalized peak area below $30 \%$ or close to this value (Table 5). Enolase from S. cerevisiae (ENO1) and human enolase alpha
(ENOA) were used as control proteins, whose abundance is not expected to be modulated. ENO1 was added as standard in samples prior to acquisition (see the Experimental Section), while ENOA was not found among the significant modulated proteins in both $\Delta \mathrm{Np} 63$ and TAp63 data sets. Mitochondrial heat shock proteins (HSP10, HSP60, and HSP71), included in mitochondrion and organelle lumen cluster by DAVID analysis and represented among the modulated nodes in network 1 of IPA analysis in TAp63 experiment, were confirmed to be downregulated with respect to CTRL condition by targeted label-free experiment. Down-regulation of HSP10 was also confirmed for $\Delta$ Np63 experiment. UGDH and MDHM, reported in network 1 of TAp63 IPA analysis and members of the PANTHER biological process called generation of precursor metabolites and energy, were found to be down-regulated in TAP63 by labeled approach. These enzymes showed a decrement with respect to control cells also in the targeted analysis, although the trend was more evident in the case of UGDH rather than in 


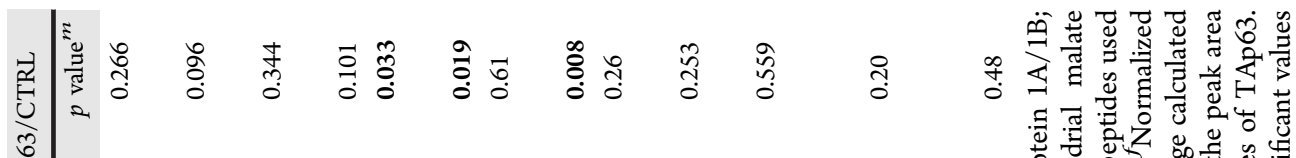

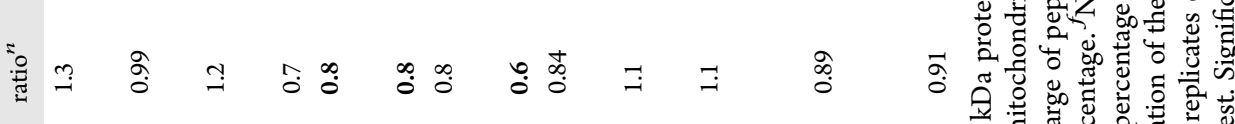

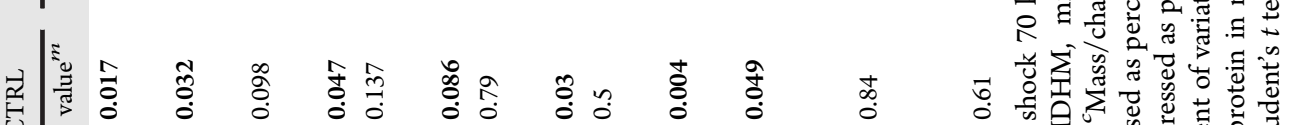

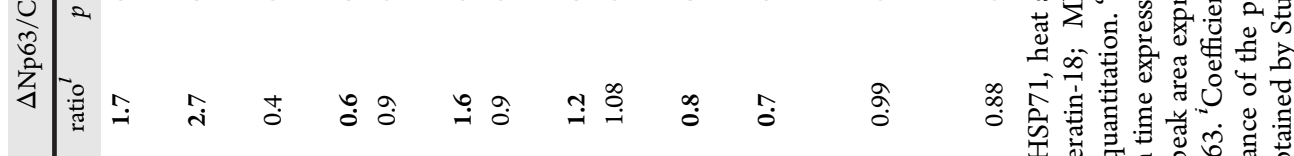

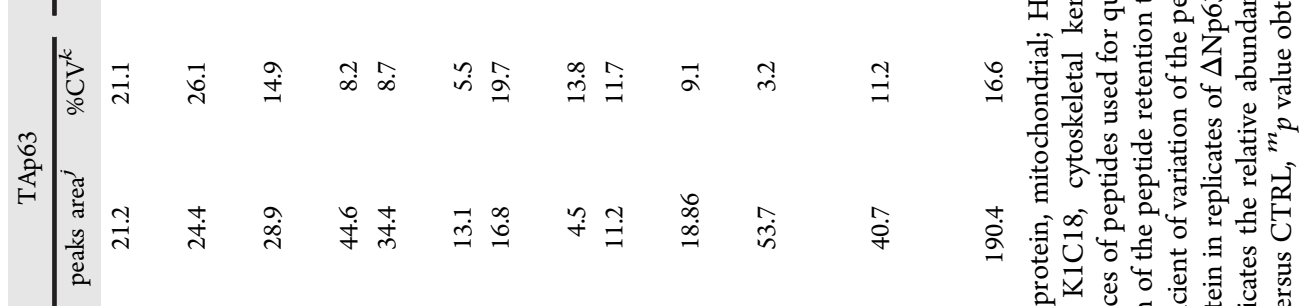

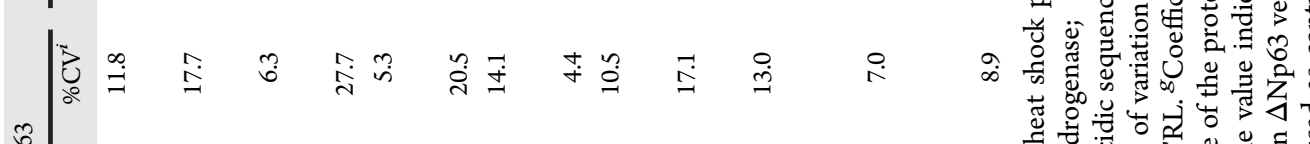

خ্خ.

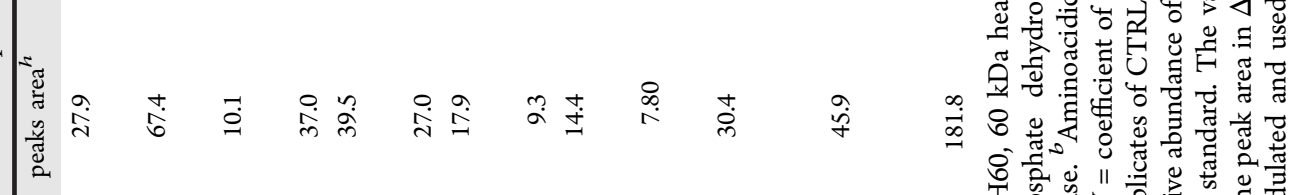

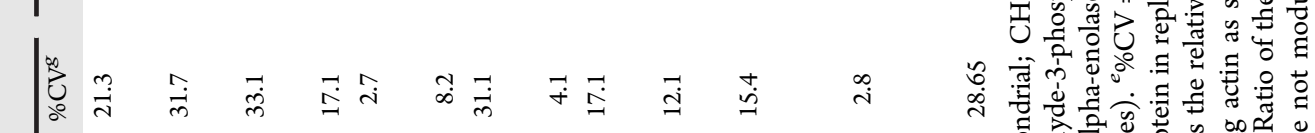

突

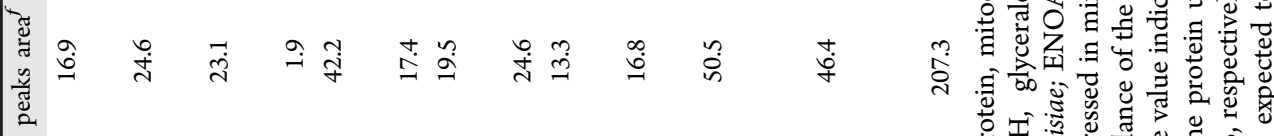
完田

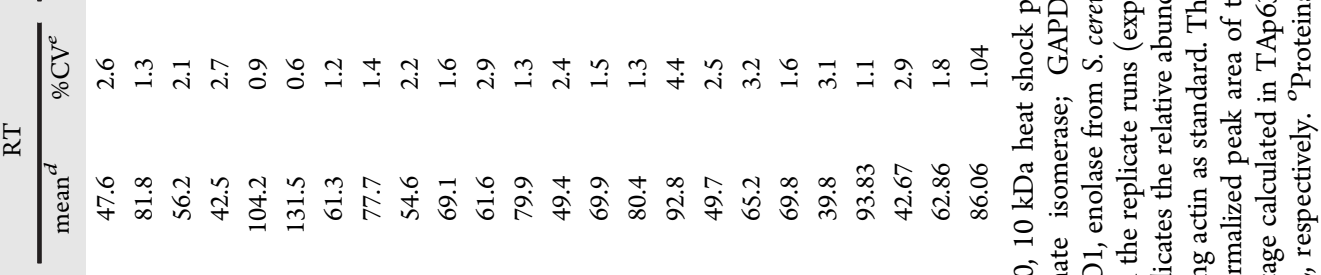

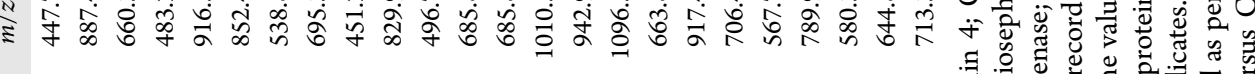

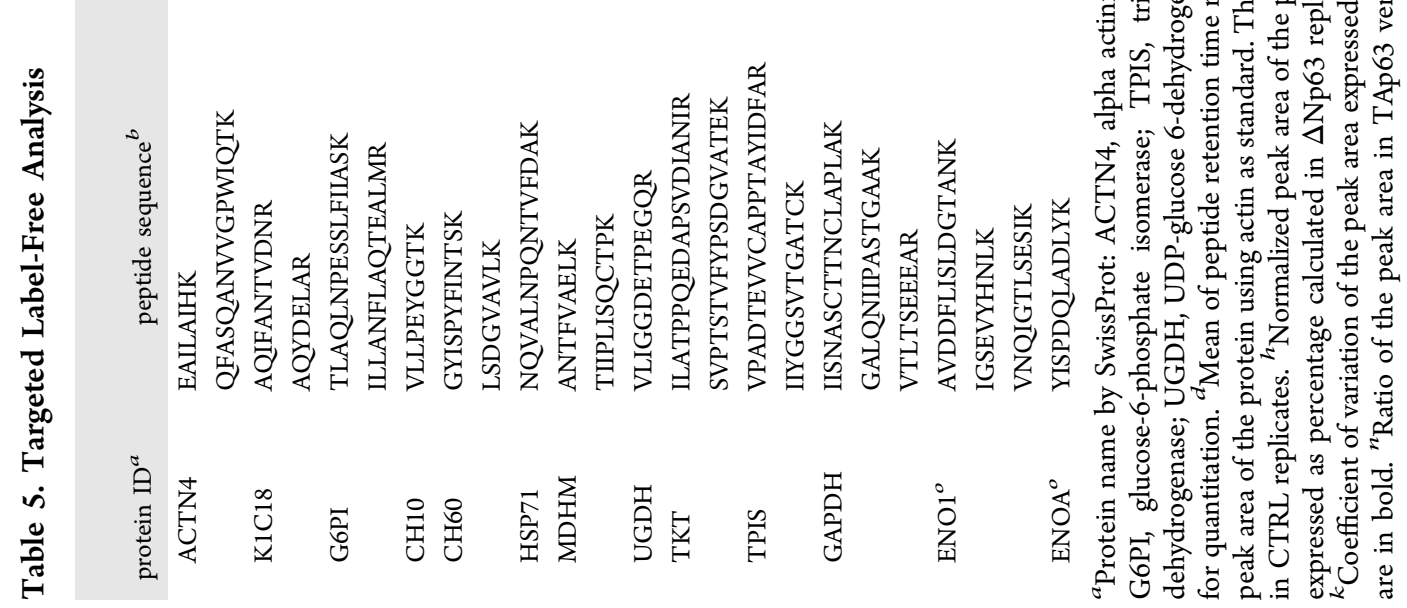


MDHM. TKT, belonging to pentose phosphate pathway (PPP), was found to be decreased in label-free analysis in TAp63 overexpressing cells, as already observed by labeled approach. Trends of ACTN4, K1C18, and G6PI, included in network 1 of $\Delta \mathrm{Np} 63$, were also confirmed in this validating phase: ACTN4 and K1C18 showed a marked increment in $\Delta \mathrm{Np63}$, whereas G6PI was decreased with respect to control condition.

\section{Targeted Metabolomics Analysis}

To better characterize the metabolic state of TAp63 and $\Delta \mathrm{Np} 63$ expressing cells, we performed a targeted metabolomics analysis, evaluating the cellular relative abundance of five relevant metabolites for the reported biochemical pathways by monitoring their mass spectrometry transitions: glucose 6phosphate (G6P), glyceraldehyde 3-phosphate (G3P), phosphoenolpyruvate (PEP), lactate (L), and malate (M) (Figure 6B). Results showed significant accumulation of G6P and G3P in $\Delta \mathrm{Np} 63$ cells, while these metabolites were less abundant in TAp63 cells, with respect to control condition. Accumulation of substrates of the first steps of glycolysis, such as G6P and G3P, was associated with decreased levels of G6PI, TPIS, and GAPDH in $\Delta \mathrm{Np} 63$ cells. G6PI was found to be down-regulated by both labeled and unlabeled proteomic analysis, while TPIS and GAPDH were reported only for the label-free proteomic strategy, although in the labeled approach TPIS showed a fold change of 0.8 with respect to control conditions, which was omitted in the corresponding table because under the selected threshold for ratio. These results may be indicative of a slower rate of the first steps of glycolysis under this condition with respect to control cells. In anaerobic glycolysis, lactate dehydrogenase (LDHA) reduces pyruvate to produce lactate (L), using $\mathrm{NAD}$ as coenzyme. In $\Delta \mathrm{Np} 63$ cells, a significant increment of $\mathrm{L}$ was not observed by targeted metabolomics analysis, and insignificant modulation of LDHA protein was detected (Figure 6C). Moreover, in these cells, we did not detect a modulation in protein level of pyruvate kinase (PKM2) (Figure 6C), a key regulatory enzyme of glycolytic pathway that catalyzes the transfer of a phosphate group from PEP to ADP, yielding one molecule of pyruvate and one molecule of ATP. Furthermore, PPP may be less favored in $\Delta \mathrm{Np} 63$-expressing cells, as indicated by the down-regulation of glucose-6phospate-dehydrogenase (G6PD), the enzyme controlling the rate-limiting step of $\mathrm{PPP}$, as observed by Western blotting experiment (Figure 6C), and by the decrement of NADP/ NADPH ratio, which was caused by reduced NADP availability rather than enhanced NADPH production (Figure 6D,E). In TAp63 overexpressing cells, the decrease in G6P and G3P was accompanied by moderate up-regulation of G6PI and GAPDH, observed in both proteomic approaches (although the fold change of 1.22 for GAPDH was not reported in Table 1 because it was under the threshold fixed for ratio) and TPIS only in label-free approach, underlining a possible opposite effect of the two p63 isoforms on glycolysis. Glycolysis may be accelerated in TAp63, as also indicated by up-regulation of PKM2, detected by Western blotting (Figure 6C), which rapidly converts PEP to pyruvate. Unlike $\Delta \mathrm{Np} 63$ cells, under TAp63 condition PEP, $\mathrm{L}$ and $\mathrm{M}$ were significantly less abundant with respect to control. LDHA was lightly upregulated, while modulation of G6PD was not detected in TAp63 cells by Western blotting (Figure 6C). The NADP/ $\mathrm{NADPH}$ ratio was approximately the same as that determined in control cells (Figure 6D,E). Interestingly, the reduced amount of malate, a TCA intermediate, was associated with the reduced levels of two TCA cycle enzymes, such as succinate dehydrogenase (DHSA), reported only in labeled proteomic analysis, and MDHM, in both labeled and label-free proteomic analysis.

\section{DISCUSSION}

On the basis of the knowledge of p63's role in the regulation of epithelial cell stemness and differentiation, it is reasonable to suspect that it may also play a role in regulating the phenotypic characteristics of CSCs through the control of several molecular pathways, including self-renewal and differentiation processes. ${ }^{23}$ Recent studies reported that $\Delta \mathrm{Np} 63$ isoforms can regulate the mRNA expression and splicing of CD44, a surface glycoprotein marking CSCs in various epithelial tumors including HNSCC and breast cancer. ${ }^{52} \Delta \mathrm{Np} 63 \alpha$ induces a stem-cell phenotype in the MCF7 breast cancer cell line, and it has been suggested that it could be a marker of breast CSC. ${ }^{53}$ Recently, it was reported that $\Delta \mathrm{Np} 63$-positive cells embody the stem/progenitor properties in prostate, bladder, and colorectal epithelium, providing a potential source of cells that can differentiate into neoplastic cells. $^{19}$

In this study, we used CSCs isolated from colon, overexpressing TAp63 $\alpha$ or $\Delta \mathrm{Np} 63 \alpha$, to evaluate cellular signaling mediated by the two isoforms, following a quantitative labeled proteomic strategy, coupled to functional in silico analysis.

A substantial number of proteins modulated by both p63 isoforms belong to cellular assembly and organization and to cellular morphology, among which there are also proteins involved in tumor progression and metastasis. Chondroitin sulfate proteoglycan 4, CSPG4, a surface protein that is known to modulate oligodendrocyte precursor cells migration ${ }^{54}$ and to be associated with invasiveness in glioma and melanoma tumors, ${ }^{55}$ was found increased in both TAp63- and $\Delta$ Np63expressing cells. Other structural proteins involved in cellular migration were found up-regulated, such as filamin-A (FLNA) in TAp63 and actinin-4 (ACTN4) in $\Delta \mathrm{Np} 63$, respectively. FLNA is an actin-binding protein playing an essential role in cytoskeletal plasticity and flexibility to respond to environmental stimuli by interacting with extracellular matrix (ECM) components. ${ }^{56}$ FLNA also interacts with many metastasisrelated proteins, and its inhibition may reduce this process, although the mechanism of action remains not completely clarified. ${ }^{57}$ ACTN4 is a component of focal adhesion, protein complexes that mediate cell migration by physically connecting the ECM to the cytoskeleton. ${ }^{58}$ These findings suggested the involvement of p63 in metastatic process of CSCs, as already observed in other cellular model of cancer. ${ }^{11,14}$

Interestingly a significant portion of modulated proteins, reported in this work, were involved in metabolic processes. A common distinct feature of cancer cells is the so-called "aerobic glycolysis", which consists of enhanced lactate production, originally known as Warburg effect. ${ }^{59}$ However, metabolic rearrangement is not limited to glycolysis but also involves the TCA cycle, $\beta$-oxidation, and anabolic metabolism in general by furnishing not only energy but also components for the synthesis of nucleotides and amino and fatty acids to sustain cellular growth and survival. ${ }^{60}$ In the recent years, it is becoming clear that different key cellular signals guide the metabolic adaptation of tumor cells, such as hypoxia inducible factor-1 (HIF-1) and PI3K/Akt/mTOR pathways, oncogenes such as c-Myc, and tumor suppressor such as p53. ${ }^{61}$ Under hypoxia condition, HIF-1 activates the transcription of genes 
encoding glucose transporters and most glycolytic enzymes, increasing the glycolytic activity of cells. Moreover, by activating pyruvate dehydrogenase kinases (PDKs), which inhibits mitochondrial pyruvate dehydrogenase complex, HIF1 reduces pyruvate flux into the TCA cycle, thus decreasing oxidative phosphorylation and oxygen consumption. ${ }^{61}$ The oncogene c-Myc activates glucose transporters, glycolytic enzymes, LDHA and PDK1, and genes involved in mitochondrial biogenesis and function, such as those associated with glutamine metabolism. ${ }^{61}$ Activation of PI3K/Akt/mTOR pathway leads to enhanced glycolytic activity by both elevated synthesis of glucose transporters and activation of HIF-1, which cooperates with $\mathrm{c}-\mathrm{Myc}$ to induce metabolic adaptation in cancer cells. ${ }^{61}$ Finally, p53 takes part in the regulation of glucose metabolism, acting on enzymes involved in glycolysis, TCA cycle, glutaminolysis, and PPP. ${ }^{61}$ In particular, p53 directly inactivates G6PD, thus inhibiting PPP, while mutated p53 is unable to perform this function, thus causing the increased consumption of glucose, typical of tumor cells. ${ }^{2} \mathrm{On}$ the contrary, TAp73, but not $\Delta \mathrm{Np} 73$, promotes biosynthesis and antioxidant protection through the induction of G6PD expression. ${ }^{58}$ Moreover, overexpression of TAp73 $\alpha$ in human osteosarcoma SAOS-2 promotes PPP process. ${ }^{64}$ Flores and colleagues demonstrated that TAp63 regulates several metabolic pathways, through which it may establish its tumor suppressor functions. ${ }^{63}$ Mice knockout of TAp63 became obese, accumulating lipid deposits in several tissues. This phenotype can be explained by an increased fatty acid synthesis associated with a concomitant decrease in fatty acid consumption. Moreover, these mice also developed defects in glucose metabolism. Furthermore, TAp63-/- mouse embryonic fibroblasts (MEFs) showed a slower rate of mitochondrial oxidative phosphorylation, which is a peculiar metabolic alteration of cancer cells, and reduced glucose uptake, which, on the contrary, is in contrast with that observed in tumor cells. $^{65}$

In this study, the in silico functional analysis highlighted the modulation of cellular signaling responsible for metabolic adaptation in the cancer cell, such as c-Myc and PI3K/Akt/ mTOR, in both TAp63- and $\Delta$ Np63-overexpressing cells, and p53, only in $\Delta \mathrm{Np} 63$-expressing cells. Proteins and metabolites of glycolysis were modulated in TAp63- and $\Delta \mathrm{Np} 63$-expressing cells but with opposite trends. In TAp63-overexpressing cells the level of glycolytic intermediates determined by targeted analysis was significantly inferior to that observed in control cells. In parallel, we observed the increased levels of glycolytic enzymes, such as G6PI, TPIS, GAPDH, and PKM2. G6PI, which catalyzes the second step of the glycolysis by the reversible isomerization of glucose-6-phosphate into fructose-6phosphate, is an essential enzyme involved in catabolic glycolysis, anabolic gluconeogenesis, and it is known to influence tumor cell growth. ${ }^{60}$ Deficiency of TPIS, another essential glycolytic enzyme, is associated with nonspherocytic hemolytic anemia and a severe neurological disorder, while its up-regulation has been reported in several cancers, including lung, liver, colon, breast, bone, and prostate. ${ }^{60}$ Oncoproteomics studies showed that also GAPDH is overexpressed in various neoplasias. ${ }^{60}$ In addition to glycolysis, GAPDH is involved in different biological functions, such as DNA repair and telomeric DNA binding, transcriptional regulation, membrane fusion, RNA binding, tubulin assembly, and apoptosis induction. ${ }^{60}$ Pyruvate kinase $(\mathrm{PK})$ is a key regulatory enzyme, catalyzing an irreversible reaction of the glycolysis. L,
$\mathrm{R}, \mathrm{M} 1$, and $\mathrm{M} 2$ are the four PK isoenzymes in mammals. Among them, the PKM2 isoenzyme is preferentially expressed in tumor cells. ${ }^{60}$ G6PI, TPIS, and GAPDH are significantly down-regulated in $\Delta \mathrm{Np} 63$-expressing cells. Also, G6PD was detected in lower quantity in $\Delta \mathrm{Np} 63$ as compared with control and TAp63 conditions. Moreover, the down-regulation of TCA cycle enzymes, such as DHSA and MDHM, and the lower level of malate may be suggestive of a perturbed mitochondrial oxidative phosphorylation in TAp63- expressing cells. Modulation of other proteins associated with mitochondrion, such as HSP10, HSP60, and HSP71, was indicative of an altered function of this organelle, particularly in TAp63-expressing cells.

Mitochondria play a key role not only in energy production but also in the cross-talk of metabolic pathways and signals for apoptosis and autophagy. ${ }^{66,67}$ Mitochondrial functions are carried out by continuous signal exchanges both from nucleus to mitochondrion, anterograde signaling, and from mitochondrion to nucleus, retrograde signaling. ${ }^{66}$ An example of retrograde signaling is represented by the mitochondrial unfolded protein response, originated from the efflux of peptides from damaged mitochondrial matrix proteins to the cytosol, which is mediated by mitochondrial HSPs. Mitochondrial chaperones promote protein folding and proteases that degrade misfolded proteins, leading to more efficient mitochondrial function and biogenesis. ${ }^{66}$

The cross-talk of the mitochondrial proteins with the nuclear encoded proteins is a fundamental task of Mitochondrial Proteome Initiative (mt-HPP), ${ }^{68}$ which will strictly cooperate with the Biology/Disease Human Proteome Project (B/DHPP $){ }^{69}$ one of the most recent initiatives launched by the Human Proteome Organization. The present study provides initial evidence toward dissecting p63 functions in CSCs, although additional studies are required to go deeper inside this issue to achieve new insight into the signaling pathways beyond the differences in metabolism response correlated to TAp63 or $\Delta$ Np63 expression. Nevertheless, evidence described here could be matter of debate inside the scientific community involved in both mt-HPP and B/D-HPP.

In conclusion, in this work, we employed a proteomic study, by both labeled and unlabeled approaches, coupled to bioinformatics and targeted metabolomics analysis to dissect the intracellular pathways triggered by TAp63 or $\Delta \mathrm{Np} 63$ isoforms in human CSCs line isolated from colon cancer. Our results indicate that p63 is implicated in a wide range of biological processes, including metabolism. Interestingly, TAp63-overexpressing cells are more glycolytic active than $\Delta$ Np63 cells, indicating that the two isoforms may regulate the key steps of glycolysis in an opposite manner. Further investigations are necessary to elucidate the underlying molecular mechanisms determining glycolysis regulation by TAp63 and $\Delta$ Np63 isoforms.

\section{ASSOCIATED CONTENT}

\section{Supporting Information}

Supplementary Table 1S: Peptides identification of D0 and D2 samples. Supplementary Table 2S: Peptide table of differentially expressed proteins identified in TAp63 data set. Supplementary Table 3S: Peptide table of differentially expressed proteins identified in $\Delta$ Np63 data set. Supplementary Table 4S: Cluster Analysis by DAVID for TAp63 data set. Supplementary Table 5S: Cluster Analysis by DAVID for $\Delta \mathrm{Np} 63$ data set. 
Supplementary Table 6S: Protein identified by label-free $\mathrm{MS}^{\mathrm{e}}$ analysis. Supplementary Table 7S: spectra of proteins identified with single peptide. Figure 1S: Data quality evaluation of labelfree $\mathrm{MS}^{\mathrm{e}}$ analysis reproducibility. This material is available free of charge via the Internet at http://pubs.acs.org.

\section{AUTHOR INFORMATION}

\section{Corresponding Authors}

*A.U.: E-mail: andrea.urbani@uniroma2.it.

*V.D.L.: E-mail: delaurenzi@unich.it.

\section{Author Contributions}

$\nabla_{\text {A.U. and V.D.L. have been acting as senior investigators and }}$ should be considered equal last authors.

Notes

The authors declare no competing financial interest.

\section{ACKNOWLEDGMENTS}

V.D.L. was supported by grant AIRC 11450 and Ministero Sanita' Finalizzata 2009. A.U. was supported by MIUR grant RBAP11WCRZ_003. We thank the PRIDE team (http://www. ebi.ac.uk/pride) for helpful assistance in mass spectrometry data uploading.

\section{REFERENCES}

(1) Levrero, M.; De Laurenzi, V.; Costanzo, A.; Gong, J.; Wang, J. Y.; Melino, G. The p53/p63/p73 family of transcription factors: overlapping and distinct functions. J. Cell Sci. 2000, 113 (Pt 10), 1661-1670.

(2) De Laurenzi, V.; Melino, G. Evolution of functions within the p53/p63/p73 family. Ann. N.Y. Acad. Sci. 2000, 926, 90-100.

(3) Muller, P. A.; Vousden, K. H. p53 mutations in cancer. Nat. Cell Biol. 2013, 15 (1), 2-8.

(4) Allocati, N.; Di Ilio, C.; De Laurenzi, V. p63/p73 in the control of cell cycle and cell death. Exp. Cell Res. 2012, 318 (11), 1285-1290.

(5) Candi, E.; Dinsdale, D.; Rufini, A.; Salomoni, P.; Knight, R. A.; Mueller, M.; Krammer, P. H.; Melino, G. TAp63 and DeltaNp63 in cancer and epidermal development. Cell Cycle 2007, 6 (3), 274-285.

(6) Graziano, V.; De Laurenzi, V. Role of p63 in cancer development. Biochim. Biophys. Acta 2011, 1816 (1), 57-66.

(7) Nylander, K.; Vojtesek, B.; Nenutil, R.; Lindgren, B.; Roos, G.; Zhanxiang, W.; Sjöström, B.; Dahlqvist, A.; Coates, P. J. Differential expression of p63 isoforms in normal tissues and neoplastic cells. $J$ Pathol. 2002, 198 (4), 417-427.

(8) Su, X.; Chakravarti, D.; Flores, E. R. p63 steps into the limelight: crucial roles in the suppression of tumorigenesis and metastasis. Nat Rev Cancer. 2013, 13 (2), 136-143.

(9) Di Como, C. J.; Urist, M. J.; Babayan, I.; Drobnjak, M.; Hedvat, C. V.; Teruya-Feldstein, J.; Pohar, K.; Hoos, A.; Cordon-Cardo, C. p63 expression profiles in human normal and tumor tissues. Clin. Cancer Res. 2002, 8 (2), 494-501.

(10) Higashikawa, K.; Yoneda, S.; Tobiume, K.; Saitoh, M.; Taki, M.; Mitani, Y.; Shigeishi, H.; Ono, S.; Kamata, N. DeltaNp63alphadependent expression of Id-3 distinctively suppresses the invasiveness of human squamous cell carcinoma. Int J Cancer. 2009, 124 (12), 2837-2844.

(11) Tucci, P.; Agostini, M.; Grespi, F.; Markert, E. K.; Terrinoni, A.; Vousden, K. H.; Muller, P. A.; Dötsch, V.; Kehrloesser, S.; Sayan, B. S.; Giaccone, G.; Lowe, S. W.; Takahashi, N.; Vandenabeele, P.; Knight, R. A.; Levine, A. J.; Melino, G. Loss of p63 and its microRNA-205 target results in enhanced cell migration and metastasis in prostate cancer. Proc Natl Acad Sci U S A. 2012, 109 (38), 15312-15317.

(12) Su, X.; Chakravarti, D.; Cho, M. S.; Liu, L.; Gi, Y. J.; Lin, Y. L.; Leung, M. L.; El-Naggar, A.; Creighton, C. J.; Suraokar, M. B.; Wistuba, I.; Flores, E. R. TAp63 suppresses metastasis through coordinate regulation of Dicer and miRNAs. Nature 2010, 467 (7318), 986-90.

(13) Gressner, O.; Schilling, T.; Lorenz, K.; Schulze Schleithoff, E.; Koch, A.; Schulze-Bergkamen, H.; Lena, A. M.; Candi, E.; Terrinoni, A.; Catani, M. V.; Oren, M.; Melino, G.; Krammer, P. H.; Stremmel, W.; Müller, M. TAp63alpha induces apoptosis by activating signaling via death receptors and mitochondria. EMBO J. 2005, 24 (13), 24582471.

(14) Melino, G. p63 is a suppressor of tumorigenesis and metastasis interacting with mutant p53. Cell Death Differ. 2011, 18 (9), 14871499.

(15) Yang, A.; Schweitzer, R.; Sun, D.; Kaghad, M.; Walker, N.; Bronson, R. T.; Tabin, C.; Sharpe, A.; Caput, D.; Crum, C.; McKeon, F. p63 is essential for regenerative proliferation in limb, craniofacial and epithelial development. Nature 1999, 398 (6729), 714-718.

(16) Mills, A. A.; Zheng, B.; Wang, X. J.; Vogel, H.; Roop, D. R.; Bradley, A. p63 is a p53 homologue required for limb and epidermal morphogenesis. Nature 1999, 398 (6729), 708-713.

(17) Karni-Schmidt, O.; Castillo-Martin, M.; Shen, T. H.; Gladoun, N.; Domingo-Domenech, J.; Sanchez-Carbayo, M.; Li, Y.; Lowe, S.; Prives, C.; Cordon-Cardo, C. Distinct expression profiles of p63 variants during urothelial development and bladder cancer progression. Am. J. Pathol. 2011, 178 (3), 1350-1360.

(18) Romano, R. A.; Smalley, K.; Magraw, C.; Serna, V. A.; Kurita, T.; Raghavan, S.; Sinha, S. $\Delta \mathrm{Np} 63$ knockout mice reveal its indispensable role as a master regulator of epithelial development and differentiation. Development 2012, 139 (4), 772-82.

(19) Pignon, J. C.; Grisanzio, C.; Geng, Y.; Song, J.; Shivdasani, R. A.; Signoretti, S. p63-expressing cells are the stem cells of developing prostate, bladder, and colorectal epithelia. Proc Natl Acad Sci U S A. 2013, 110 (20), 8105-8110.

(20) Senoo, M.; Pinto, F.; Crum, C. P.; McKeon, F. p63 is essential for the proliferative potential of stem cells in stratified epithelia. Cell 2007, 129 (3), 523-536.

(21) Koster, M. I.; Dai, D.; Marinari, B.; Sano, Y.; Costanzo, A.; Karin, M.; Roop, D. R. p63 induces key target genes required for epidermal morphogenesis. Proc Natl Acad Sci U S A. 2007, 104 (9), 3255-60.

(22) Su, X.; Paris, M.; Gi, Y. J.; Tsai, K. Y.; Cho, M. S.; Lin, Y. L.; Biernaskie, J. A.; Sinha, S.; Prives, C.; Pevny, L. H.; Miller, F. D.; Flores, E. R. TAp63 prevents premature aging by promoting adult stem cell maintenance. Cell Stem Cell. 2009, 5 (1), 64-75.

(23) Nekulova, M.; Holcakova, J.; Coates, P.; Vojtesek, B. The role of p63 in cancer, stem cells and cancer stem cells. Cell Mol Biol Lett. 2011, 16 (2), 296-327.

(24) O’Brien, C. A.; Pollett, A.; Gallinger, S.; Dick, J. E. A human colon cancer cell capable of initiating tumour growth in immunodeficient mice. Nature 2007, 445 (7123), 106-110.

(25) Ricci-Vitiani, L.; Lombardi, D. G.; Pilozzi, E.; Biffoni, M.; Todaro, M.; Peschle, C.; De Maria, R. Identification and expansion of human colon-cancer-initiating cells. Nature 2007, 445 (7123), 111115 .

(26) Todaro, M.; Francipane, M. G.; Medema, J. P.; Stassi, G. Colon cancer stem cells: promise of targeted therapy. Gastroenterology 2010, 138 (6), 2151-2162.

(27) Scatena, R.; Bottoni, P.; Giardina, B. Circulating tumour cells and cancer stem cells: a role for proteomics in defining the interrelationships between function, phenotype and differentiation with potential clinical applications. Biochim. Biophys. Acta 2013, 1835 (2), 129-143.

(28) Todaro, M.; Alea, M. P.; Di Stefano, A. B.; Cammareri, P.; Vermeulen, L.; Iovino, F.; Tripodo, C.; Russo, A.; Gulotta, G.; Medema, J. P.; Stassi, G. Colon cancer stem cells dictate tumor growth and resist cell death by production of interleukin. Cell Stem Cell 2007, 4 (1), 389-402.

(29) Candi, E.; Rufini, A.; Terrinoni, A.; Dinsdale, D.; Ranalli, M.; Paradisi, A.; De Laurenzi, V.; Spagnoli, L. G.; Catani, M. V.; Ramadan, S.; Knight, R. A.; Melino, G. Differential roles of p63 isoforms in 
epidermal development: selective genetic complementation in p63 null mice. Cell Death Differ. 2006, 13 (6), 1037-1047.

(30) Ricci-Vitiani, L.; Pedini, F.; Mollinari, C.; Condorelli, G.; Bonci, D.; Bez, A.; Colombo, A.; Parati, E.; Peschle, C.; De Maria, R. Absence of caspase 8 and high expression of PED protect primitive neural cells from cell death. J Exp Med. 2004, 200 (10), 1257-66.

(31) Follenzi, A.; Ailles, L. E.; Bakovic, S.; Geuna, M.; Naldini, L. Gene transfer by lentiviral vectors is limited by nuclear translocation and rescued by HIV-1 pol sequences. Nat. Genet. 2000, 25 (2), 217222.

(32) Boersema, P. J.; Raijmakers, R.; Lemeer, S.; Mohammed, S.; Heck, A. J. Multiplex peptide stable isotope dimethyl labeling for quantitative proteomics. Nat Protoc. 2009, 4 (4), 484-494.

(33) Hsu, J. L.; Huang, S. Y.; Chow, N. H.; Chen, S. H. Stableisotope dimethyl labeling for quantitative proteomics. Anal. Chem. 2003, 75 (24), 6843-6852.

(34) Boutilier, J. M.; Warden, H.; Doucette, A. A.; Wentzell, P. D. Chromatographic behaviour of peptides following dimethylation with H2/D2-formaldehyde: implications for comparative proteomics. $J$ Chromatogr B Analyt Technol Biomed Life Sci. 2012, 1 (908), 59-66.

(35) Levi Mortera, S.; Dioni, I.; Greco, V.; Neri, C.; Rovero, P.; Urbani. A.; pH-regulated formation of side products in the reductive amination approach for differential labeling of peptides in relative quantitative experiments. Electrophoresis 2014, 00, 1-9.in press.

(36) De Canio, M.; D’Aguanno, S.; Sacchetti, C.; Petrucci, F.; Cavagni, G.; Nuccetelli, M.; Federici, G.; Urbani, A.; Bernardini, S. Novel IgE recognized components of Lolium perenne pollen extract: comparative proteomics evaluation of allergic patients sensitization profiles. J Proteome Res. 2009, 8 (9), 4383-4391.

(37) Chick, J. M.; Haynes, P. A.; Molloy, M. P.; Bjellqvist, B.; Baker, M. S.; Len, A. C. Characterization of the rat liver membrane proteome using peptide immobilized $\mathrm{pH}$ gradient isoelectric focusing. J Proteome Res. 2008, 7 (3), 1036-1045.

(38) Cantor, D.; Slapetova, I.; Kan, A.; McQuade, L. R.; Baker, M. S. Overexpression of $\alpha \mathrm{v} \beta 6$ integrin alters the colorectal cancer cell proteome in favor of elevated proliferation and a switching in cellular adhesion that increases invasion. J Proteome Res. 2013, 12 (6), 24772490.

(39) Mendes, M.; Pérez-Hernandez, D.; Vázquez, J.; Coelho, A. V.; Cunha, C. Proteomic changes in HEK-293 cells induced by hepatitis delta virus replication. J Proteomics. 2013, 89, 24-38.

(40) Vizcaíno, J. A.; Côté, R. G.; Csordas, A.; Dianes, J. A.; Fabregat, A.; Foster, J. M.; Griss, J.; Alpi, E.; Birim, M.; Contell, J.; O’Kelly, G.; Schoenegger, A.; Ovelleiro. D.; Pérez-Riverol, Y.; Reisinger, F.; Ríos, D.; Wang, R.; Hermjakob, H. The PRoteomics IDEntifications (PRIDE) database and associated tools: status in 2013. Nucleic Acids Res. 2013, 41(Database issue):D1063-9. doi: 10.1093/nar/gks1262.

(41) Côté, R. G.; Griss, J.; Dianes, J. A.; Wang, R.; Wright, J. C.; van den Toorn, H. W.; van Breukelen, B.; Heck, A. J.; Hulstaert, N.; Martens, L.; Reisinger, F.; Csordas, A.; Ovelleiro, D.; Perez-Rivevol, Y.; Barsnes, H.; Hermjakob, H.; Vizcaíno, J. A. The PRoteomics IDEntification (PRIDE) Converter 2 framework: an improved suite of tools to facilitate data submission to the PRIDE database and the ProteomeXchange consortium. Mol Cell Proteomics. 2012, 11 (12), $1682-1689$.

(42) D’Aguanno, S.; D’Alessandro, A.; Pieroni, L.; Roveri, A.; Zaccarin, M.; Marzano, V.; De Canio, M.; Bernardini, S.; Federici, G.; Urbani, A. New insights into neuroblastoma cisplatin resistance: a comparative proteomic and meta-mining investigation. J Proteome Res. 2011, 10 (2), 416-428.

(43) D’Alessandro, A.; D’Aguanno, S.; Cencioni, M. T.; Pieroni, L.; Diamantini, A.; Battistini, L.; Longone, P.; Spalloni, A.; De Laurenzi, V.; Bernardini, S.; Federici, G.; Urbani, A. Protein repertoire impact of Ubiquitin-Proteasome System impairment: insight into the protective role of beta-estradiol. J Proteomics. 2012, 75 (4), 1440-1453.

(44) D’Aguanno, S.; D’Agnano, I.; De Canio, M.; Rossi, C.; Bernardini, S.; Federici, G.; Urbani, A. Shotgun proteomics and network analysis of neuroblastoma cell lines treated with curcumin. Mol Biosyst. 2012, 8 (4), 1068-1077.
(45) MacLean, B.; Tomazela, D. M.; Shulman, N.; Chambers, M.; Finney, G. L.; Frewen, B.; Kern, R.; Tabb, D. L.; Liebler, D. C.; MacCoss, M. J. Skyline: an open source document editor for creating and analyzing targeted proteomics experiments. Bioinformatics 2010, 26 (7), 966-968.

(46) De Canio, M.; Soggiu, A.; Piras, C.; Bonizzi, L.; Urbani, A.; Galli, A.; Roncada, P. Differential protein profile in sexed bovine semen: shotgun proteomics investigation Mol. Biosyst. 2013, Epub ahead of print, DOI: 10.1039/C3MB70306A

(47) Marzano, V.; Santini, S.; Rossi, C.; Zucchelli, M.; D’Alessandro, A.; Marchetti, C.; Mingardi, M.; Stagni, V.; Barilà, D.; Urbani, A. Proteomic profiling of ATM kinase proficient and deficient cell lines upon blockage of proteasome activity. J Proteomics 2012, 75 (15), $4632-4646$.

(48) Munarriz, E.; Barcaroli, D.; Stephanou, A.; Townsend, P. A.; Maisse, C.; Terrinoni, A.; Neale, M. H.; Martin, S. J.; Latchman, D. S.; Knight, R. A.; Melino, G.; De Laurenzi, V. PIAS-1 is a checkpoint regulator which affects exit from G1 and G2 by sumoylation of p73. Mol. Cell. Biol. 2004, 24 (24), 10593-10610.

(49) Schultze, S. M.; Hemmings, B. A.; Niessen, M.; Tschopp, O. PI3K/AKT, MAPK and AMPK signalling: protein kinases in glucose homeostasis. Expert Rev Mol Med. 2012, DOI: 10.1017/ S1462399411002109.

(50) Koizumi, T.; Nakatsuji, H.; Fukawa, T.; Avirmed, S.; Fukumori, T.; Takahashi, M.; Kanayama, H. The role of actinin-4 in bladder cancer invasion. Urology 2010, 75 (2), 357-364.

(51) Neisch, A. L.; Fehon, R. G. Ezrin, Radixin and Moesin: key regulators of membrane-cortex interactions and signaling. Curr Opin Cell Biol. 2011, 23 (4), 377-382.

(52) Boldrup, L.; Coates, P. J.; Gu, X.; Nylander, K. DeltaNp63 isoforms regulate CD44 and keratins 4, 6, 14 and 19 in squamous cell carcinoma of head and neck. J. Pathol. 2007, 213, 384-391.

(53) Du, Z.; Li, J.; Wang, L.; Bian, C.; Wang, Q.; Liao, L.; Dou, X.; Bian, X.; Zhao, R. C. Overexpression of $\Delta \mathrm{Np} 63 \alpha$ induces a stem cell phenotype in MCF7 breast carcinoma cell line through the Notch pathway. Cancer Sci. 2010, 101, 2417-2424.

(54) Binamé, F.; Sakry, D.; Dimou, L.; Jolivel, V.; Trotter, J. NG2 regulates directional migration of oligodendrocyte precursor cells via Rho GTPases and polarity complex proteins. J. Neurosci. 2013, 33 (26), 10858-1074.

(55) Campoli, M.; Ferrone, S.; Wang, X. Functional and clinical relevance of chondroitin sulfate proteoglycan 4. Adv. Cancer Res. 2010, 109, 73-121.

(56) Yue, J.; Huhn, S.; Shen, Z. Complex roles of filamin-A mediated cytoskeleton network in cancer progression. Cell Biosci. 2013, 3 (1), 7 DOI: $10.1186 / 2045-3701-3-7$.

(57) Jiang, X.; Yue, J.; Lu, H.; Campbell, N.; Yang, Q.; Lan, S.; Haffty, B. G.; Yuan, C.; Shen, Z. Inhibition of filamin-A reduces cancer metastatic potential. Int J Biol Sci. 2013, 9 (1), 67-77.

(58) Hamill, K. J.; Hopkinson, S. B.; Skalli, O.; Jones, J. C. Actinin-4 in keratinocytes regulates motility via an effect on lamellipodia stability and matrix adhesions. FASEB J. 2013, 27 (2), 546-556.

(59) Warburg, O. On the origin of cancer cells. Science 1956, 123, 309-314.

(60) Scatena, R.; Bottoni, P.; Pontoglio, A.; Giardina, B. Revisiting the Warburg effect in cancer cells with proteomics. The emergence of new approaches to diagnosis, prognosis and therapy. Proteomics Clin Appl. 2010, 4 (2), 143-158.

(61) Cairns, R. A.; Harris, I. S.; Mak, T. W. Regulation of cancer cell metabolism. Nat Rev Cancer. 2011, 11 (2), 85-95.

(62) Jiang, P.; Du, W.; Wang, X.; Mancuso, A.; Gao, X.; Wu, M.; Yang, X. p53 regulates biosynthesis through direct inactivation of glucose-6-phosphate dehydrogenase. Nat. Cell Biol. 2011, 13 (3), 310-316.

(63) Du, W.; Jiang, P.; Mancuso, A.; Stonestrom, A.; Brewer, M. D.; Minn, A. J.; Mak, T. W.; Wu, M.; Yang, X. TAp73 enhances the pentose phosphate pathway and supports cell proliferation. Nat. Cell Biol. 2013, 15 (8), 991-1000. 
(64) D’Alessandro, A.; Marrocco, C.; Rinalducci, S.; Peschiaroli, A.; Timperio, A. M.; Bongiorno-Borbone, L.; Finazzi Agrò, A.; Melino, G.; Zolla, L. Analysis of TAp73-dependent signaling via omics technologies. J Proteome Res. 2013, 12 (9), 4207-4220.

(65) Su, X.; Gi, Y. J.; Chakravarti, D.; Chan, I. L.; Zhang, A.; Xia, X.; Tsai, K. Y.; Flores, E. R. TAp63 is a master transcriptional regulator of lipid and glucose metabolism. Cell Metab. 2012, 16 (4), 511-525.

(66) Guha, M.; Avadhani, N. G. Mitochondrial retrograde signaling at the crossroads of tumor bioenergetics, genetics and epigenetics. Mitochondrion. 2013, 13 (6), 577-591.

(67) Bottoni, P.; Giardina, B.; Pontoglio, A.; Scarà, S.; Scatena, R. Mitochondrial proteomic approaches for new potential diagnostic and prognostic biomarkers in cancer. Adv. Exp. Med. Biol. 2012, 942, 42340.

(68) Urbani, A.; De Canio, M.; Palmieri, F.; Sechi, S.; Bini, L.; Castagnola, M.; Fasano, M.; Modesti, A.; Roncada, P.; Timperio, A. M.; Bonizzi, L.; Brunori, M.; Cutruzzolà, F.; De Pinto, V.; Di Ilio, C.; Federici, G.; Folli, F.; Foti, S.; Gelfi, C.; Lauro, D.; Lucacchini, A.; Magni, F.; Messana, I.; Pandolfi, P. P.; Papa, S.; Pucci, P.; Sacchetta, P. Italian Mt-Hpp Study Group-Italian Proteomics Association ( www. itpa.it).The mitochondrial Italian Human Proteome Project initiative (mt-HPP). Mol Biosyst. 2013, 9 (8), 1984-1992.

(69) Aebersold, R.; Bader, G. D.; Edwards, A. M.; van Eyk, J. E.; Kussmann, M.; Qin, J.; Omenn, G. S. The biology/disease-driven human proteome project (B/D-HPP): enabling protein research for the life sciences community. J Proteome Res. 2013, 12 (1), 23. 